\title{
Tempo-spatial variation of emission inventories of speciated volatile organic compounds from on-road vehicles in China
}

\author{
H. Cai and S. D. Xie \\ College of Environmental Science and Engineering, State Key Joint Laboratory of Environmental Simulation and Pollution \\ Control, Peking University, Beijing, China
}

Received: 16 April 2009 - Published in Atmos. Chem. Phys. Discuss.: 5 May 2009

Revised: 26 August 2009 - Accepted: 30 August 2009 - Published: 22 September 2009

\begin{abstract}
Emission inventories of sixty-seven speciated non-methane volatile organic compounds (NMVOC) from on-road vehicles in China were estimated for the period of 1980-2005, using seven NMVOC emission profiles, which were summarized based on local and international measurements from published literatures dealing with specific vehicle categories running under particular modes.

Results show an exponential growth trend of China's historical emissions of alkanes, alkenes, alkines, aromatics and carbonyls during the period of 1980-2005, increasing from $63.9,39.3,6.9,36.8$ and 24.1 thousand tons, respectively, in 1980 to $2778.2,1244.5,178.7,1351.7$ and 406.0 thousand tons, respectively, in 2005, which coincided well with China's economic growth. Emission inventories of alkenes, aromatics and carbonyls were gridded at a high resolution of $40 \mathrm{~km} \times 40 \mathrm{~km}$ for air quality simulation and health risk evaluation, using the geographic information system (GIS) methodology. Spatial distribution of speciated NMVOC emissions shows a clear difference in emission densities between developed eastern and relatively underdeveloped western and inland China. Besides, the appearance and expansion of high-emission areas was another notable characteristic of spatial distribution of speciated NMVOC emissions during the period.
\end{abstract}

Emission contributions of vehicle categories to speciated NMVOC groups showed annual variation, due to the variance in the provincial emissions and in the relative fractions of the seven emission profiles adopted at the provincial level. Highly reactive and toxic compounds accounted for high proportions of emissions of speciated NMVOC groups. The most abundant compounds were isopentane, pentane and butane from alkanes; ethene, propene, 2-methyl2-butene and ethyne from alkenes and alkines; benzene,

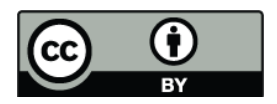

Correspondence to: S. D. Xie (sdxie@pku.edu.cn) toluene, ethylbenzene, o-xylene, and m,p-xylene (BTEX) and 1,2,4-trimethylbenzene from aromatics and formaldehyde, acetaldehyde, benzaldehyde and acetone from carbonyls.

\section{Introduction}

Concerns about non-methane volatile organic compounds (NMVOC) have increased due to their crucial role in tropospheric chemistry. Through photochemical reaction with nitrogen oxides in the atmosphere, NMVOC contribute to the production of secondary pollutants such as ozone, peroxyacetyl nitrate (PAN) and secondary organic aerosols (Odum et al., 1997; Atkinson, 2000). Different groups of NMVOC compounds differ significantly in how rapidly they react and the extent to which their reactions contribute to ozone formation. These differences in the effects on ozone formation are referred to as the ozone reactivities of NMVOC (Duffy et al., 1999). Besides, NMVOC are the main inputs to atmospheric chemistry models that study the formation and fate of photochemical oxidants in the atmosphere (Klimont et al., 2002). Therefore, compilation of speciated NMVOC emission inventories is necessary for photochemical modeling calculations and for the design of abatement strategies for ozone and secondary organic aerosols.

Speciated NMVOC profiles of major anthropogenic sources, especially the mobile source, were extensively measured (Conner et al., 1995; Duffy et al., 1999; Kourtidis et al., 1999; Hwa et al., 2002; Batterman et al., 2005; Lough et al., 2005). Recently, major source profiles of NMVOC in China were measured by Liu et al. (2008). These studies obtained fruitful results about the compositional and concentration characteristics of speciated NMVOC groups, together with the important information on the reactivities of specific NMVOC species, which was necessary for evaluating the ozone-formation potentials of NMVOC. Among the major

Published by Copernicus Publications on behalf of the European Geosciences Union. 
anthropogenic sources of NMVOC emissions, the automobile has been recognized in many countries as a primary contributor: highway vehicle emissions dominated in the USA for the period of 1970-2006, although the contribution of this sector showed a decreasing trend from $48.8 \%$ in 1970 to $14.4 \%$ in 2007 (USEPA, 2008). Similar situation appeared in UK during the period 1970-2000, with the road transport emissions accounting for $22.5-36.2 \%$ of the total emissions. Analysis of the contribution of motor vehicles to ambient hydrocarbon distributions in Switzerland concluded that the proportion of VOC from motor traffic amounted to 48 $67 \%$ (Staehelin et al., 2001). Traffic emission was recently recognized to determine the ambient NMVOC composition in a German city (Niedojadlo et al., 2007). Source apportionment of ambient VOC in Beijing revealed that gasolinerelated emissions contributed $52 \%$ to the total ambient VOC (Song et al., 2007). Despite the likely dominant contribution of on-road vehicles to NMVOC emissions in China, only limited research on providing China's database of NMVOC emissions was conducted: Composition of $\mathrm{C}_{2}-\mathrm{C}_{10}$ NMVOC in the urban atmospheres of 43 Chinese cities were measured (Barletta et al., 2005); emission inventories of total NMVOC in China for the years 1990, 1995, 2000, 2010, and 2020 were compiled (Klimont et al., 2002); an Asian emission inventory of anthropogenic emission sources for the period 1980-2020 was developed, which presented Chinese NMVOC emissions in 2000 and for 1980-2003, and the projected NMVOC emissions for 2010 and 2020 (Ohara et al., 2007); the anthropogenic NMVOC emissions in China were estimated in China for the period of 1980-2005 (Bo et al., 2008), and for the years 1994-1995 (Tonooka et al., 2001). Recently, Wei et al. (2008) compiled a speciated NMVOC emission inventory from major anthropogenic sources in China for the year 2005. However, traffic-related emission inventories of speciated NMVOC were rarely compiled in China, especially for the recently historical emissions, leaving a large information gap. Therefore, for a better understanding of the formation of ozone and other secondary oxidants and for better practices in health risk management and design of control strategies for highly reactive and toxic NMVOC, emission inventories of speciated NMVOC groups from on-road vehicles in China are compiled at the provincial level in this study, covering the period of 1980-2005, and are further allocated to the county level based on differences in local economic development levels and gridded at a high resolution of $40 \mathrm{~km} \times 40 \mathrm{~km}$ using the geographic information system (GIS) methodology. In particular, temporal variation and spatial distribution of the speciated inventories were discussed, the compositional characteristics of speciated NMVOC groups were identified, and the contributions of various vehicle categories to speciated emissions were evaluated.

\section{Methodology}

\subsection{Emissions of speciated NMVOC groups}

Emissions of speciated vehicular NMVOC groups included speed-dependent hot emissions under thermally stabilized engine and exhaust aftertreatment conditions, the warmingup phase of cold start emissions influenced by ambient temperature and average trip length (Ltrip), and the fuel evaporation emissions. Generally, roads are classified into subcategories during the compilation of the vehicular emission inventories, to simplify the complexity of the issue. Therefore, this study has classified roads in China into three types of urban, rural and freeway roads, on which the running speeds of $20 \mathrm{~km} / \mathrm{h}$ (for the period of $1990-2005$ ) and $30 \mathrm{~km} / \mathrm{h}$ (for period of 1980-1985) for urban, $40 \mathrm{~km} / \mathrm{h}$ for rural and $80 \mathrm{~km} / \mathrm{h}$ for freeway in China were adopted based on a wide review of domestic research on the characteristics of vehicle driving cycles (Liu and Ding, 2000; Yao et al., 2004, 2006; Zhang and Ruan, 2005; Xie et al., 2006; Lei, 2007; Wang et al., 2007; Ye et al., 2007), to assure the representativeness of these speeds for the three typical driving cycles in China. Besides, these speeds were assumed to stay stable during the past 25 years because the running speeds were not dependent on time and locations, but instead were determined mostly by the road grades, the vehicle conditions and traffic conditions, which overall had little effect on the increase of speed during the past few decades. Then, based on specific considerations on the detailed local vehicle populations, fleet compositions, ambient temperatures, RVP of local fuels, as well as the ratios of VMT under the three driving cycles, the NMVOC emission factors of various vehicle categories running on the said road types were calculated by the COPERT model (EEA, 2000) for each province during the studied period, to trace and reflect the temporal and spatial variation of emission factors.

We used the COPERT default value of $12.4 \mathrm{~km}$ to represent the average trip lengths of various vehicle categories, since it is proposed to use this value unless firm national estimates are available (Ntzaichristos and Samaras, 2000). Recently some domestic studies on the Ltrip revealed that the Ltrips for buses, private cars and taxies in Beijing were $8.5,24.0$ and $10.0 \mathrm{~km}$, respectively (Shi et at., 2009), and the Ltrips for buses and private cars were 9.5 and $7.2 \mathrm{~km}$, respectively, in Hangzhou, the capital city of Zhejiang province (Liu and Wang, 2004). Moreover, Zhang (2005) reported that the Ltrip was usually a little bit more than $10.0 \mathrm{~km}$ in several cities of Guangdong province. These studies could justify our adoption of the $12.4 \mathrm{~km}$ value, given the lack of more credible information.

Cold start emissions and the fuel evaporation emissions were calculated based on the standard CORINAIR methodology incorporated by COPERT model (Ntzaichristos and Samaras, 2000), and the tailpipe exhaust and evaporation emissions of each vehicle category at the provincial 
level from 1980 to 2005 were from the results of Cai and Xie (2007). Subsequently, the emissions of each specific NMVOC species were calculated based on the gross NMVOC emissions of specific vehicle category running under particular conditions and the corresponding emission profiles, using Eq. (1), which covered thirty-one provinces/autonomous regions/municipalities on the Chinese mainland, with Hong Kong Special Administrative Region, Macau Special Administrative Region, and Taiwan province excluded.

$E_{s}=\sum_{i=1}^{6}\left(Q_{\mathrm{ext}, i} \times P_{i}\right)+Q_{\mathrm{eva}} \times P_{\text {eva }}$

Where $E_{s}$ is the emission for each specific NMVOC species in a studied year; $Q_{\text {ext }, i}$ are the tailpipe exhaust NMVOC emissions of that year including hot emissions and cold start emissions under a particular condition $i$, which includes six situations corresponding to each specific vehicle category running under a normal $(20 \mathrm{~km} / \mathrm{h}$ and $40 \mathrm{~km} / \mathrm{h})$ mode or a freeway $(80 \mathrm{~km} / \mathrm{h})$ mode: (1) gasoline vehicles with TWC (three-way catalysts) running under the normal mode; (2) gasoline vehicles without TWC running under the normal mode; (3) gasoline vehicles running under the freeway mode; (4) diesel vehicles running under the normal mode; (5) diesel vehicles running under the freeway mode; and (6) motorcycles; $P_{i}$ are the six corresponding profiles of tailpipe exhaust NMVOC emissions in the above six situations; $Q_{\text {eva }}$ is the gasoline evaporation emission and $P_{\mathrm{eva}}$ is the emission profile for $Q_{\text {eva }}$.

Currently, there were few local NMVOC profiles available (Lu et al., 2003; Tsai et al., 2006; Liu et al., 2008; Tang et al., 2008), which reported the NMVOC emission profiles in Beijing and Guangzhou, and the fuel compositions in South China's Guangzhou and Zhuhai. Thus, these deficient local profiles reporting the results of limited vehicle categories under limited driving cycles were inadequate to represent emission profiles all over China, and hence were likely to cause large inaccuracy. Unfortunately, it is costly, time-consuming and meaningless to conduct measurement of every local NMVOC profile in order to obtain an adequate knowledge about the speciated NMVOC emissions in China, and it is also difficult to fulfill the purpose of reducing time and budget by sampling the exhaust and evaporation NMVOC emissions in certain cities of China to obtain representative NMVOC profiles, due to high uncertainty of assuring the appropriate volumes, locations and timing of sampling. Nevertheless, to provide reliable evidence and support for decision-makers and policy-formulators under current circumstances, the compilation and use of the seven averaged NMVOC profiles based on both local and international NMVOC profiles, in comparison with deficient local VOC profiles alone, is believed so far the best way of solving the problem of compiling speciated NMVOC emissions in China with an acceptable level of inaccuracy.
To determine each $P_{i}$ and $P_{\text {eva }}$, the NMVOC emission profiles for various vehicle categories under particular running modes were firstly surveyed from available published literatures. Secondly, the relative weight proportions of a specific measured species from all available emission profiles measured with the same vehicle category under similar measurement conditions were used to calculate a mean value using Eq. (2), which represented the relative weight proportion of that species in the emission profile to be determined. Different profiles of the same type were not assigned different weights, but instead were treated equal and simply averaged, since there was no authoritative assessment of the reliability levels of various emission profiles and all the profiles were regarded credible due to reliable measurement methods and detailed experiment procedures. Finally, the calculated mean values of all species for the particular emission profile were normalized to the total weight proportion of all species included in that profile, to be the identified relative weight ratios of various species of that emission profile. As a result, the six profiles of tailpipe exhaust emissions including sixty-seven constituents of alkanes, alkenes, alkines, carbonyl compounds and aromatics and the gasoline evaporation emission profile including forty-one constituents were determined.

$\operatorname{RWP}_{s}=\frac{\sum_{i=1}^{n} \operatorname{RWP}_{s_{i}}}{n}$

Where $\mathrm{RWP}_{s}$ is the averaged relative weight proportion of a specific species; $\operatorname{RWP}_{s_{i}}$ is one relative weight proportion of that specific species from surveyed published literatures; and $n$ is the number of surveyed published literatures that reported the relative weight proportion of that specific species.

Tables 1 and 2 show the identified profile of tailpipe exhaust emissions for gasoline vehicles with TWC running under normal mode and the gasoline evaporation emission profile, respectively. Profiles of tailpipe exhaust emissions for other vehicle categories running under particular modes are provided in the Supplementary Material (see http://www.atmos-chem-phys.net/9/6983/ 2009/acp-9-6983-2009-supplement.zip).

It is necessary to identify the TWC utilization rates before applying the corresponding emission profiles for gasoline vehicles with and without TWC on them, since the emission profiles for TWC gasoline vehicles and for non-TWC ones differed remarkably. According to a regulation formulated in China that required installing TWC on new gasoline vehicles coming into use from year 2000 (MEP, 1999), and to another regulation prescribing that unleaded gasoline would be provided for civil transportation from the beginning of year 2000 (GAQSIQ, 1999), which ensured the satisfaction of the fuel quality requirement of using TWC by gasoline vehicles, gasoline vehicles coming into use before 2000 were considered without TWC on them, and all newly-used gasoline vehicles since 2000 were considered with TWC on them. For the period of 2000-2005 when both TWC gasoline vehicles 
Table 1. The identified profile (weight \%) of tailpipe exhaust emission for gasoline vehicles with TWC running under the normal mode (55 species), based on a wide literature review.

\begin{tabular}{|c|c|c|c|c|c|c|}
\hline Species & $\begin{array}{l}\text { Schauer et al. } \\
(2002)\end{array}$ & $\begin{array}{l}\text { Duffy et al. } \\
\text { (1999) }\end{array}$ & $\begin{array}{l}\text { Liu et al. } \\
(2008)\end{array}$ & $\begin{array}{l}\text { Schmitz et al. } \\
(2000)^{\mathrm{a}}\end{array}$ & $\begin{array}{l}\text { Schmitz et al. } \\
(2000)^{\mathrm{b}}\end{array}$ & $\begin{array}{l}\text { Normalized } \\
\text { averages }\end{array}$ \\
\hline isopentane & 3.70 & $\mathrm{Nd}$ & 6.43 & 6.45 & 6.34 & 6.28 \\
\hline 2,3-dimethylbutane & 0.70 & 0.50 & 0.80 & 3.83 & 3.85 & 2.12 \\
\hline ethane & 2.54 & 2.10 & 5.64 & 0.85 & 0.84 & 2.62 \\
\hline pentane & 1.40 & 4.60 & 1.31 & 1.99 & 1.98 & 2.47 \\
\hline isooctane & 2.68 & 0.40 & 0.85 & 1.99 & 2.04 & 1.74 \\
\hline 2-methylpentane & 2.07 & 3.40 & 3.34 & 1.65 & 1.67 & 2.66 \\
\hline butane & 0.53 & 2.70 & 0.96 & 1.37 & 1.32 & 1.51 \\
\hline isobutane & 0.04 & $\mathrm{Nd}$ & 0.64 & 0.92 & 0.88 & 0.68 \\
\hline 3-methylpentane & 1.23 & 2.50 & 2.34 & 0.97 & 0.99 & 1.76 \\
\hline hexane & 0.95 & 2.20 & 1.08 & 0.89 & 0.91 & 1.32 \\
\hline 2,2-dimethylbutane & 0.26 & $\mathrm{Nd}$ & 0.10 & 0.78 & 0.76 & 0.52 \\
\hline 3-methylhexane & $\mathrm{Nd}$ & $\mathrm{Nd}$ & 0.93 & 0.70 & 0.73 & 0.86 \\
\hline 2,4-dimethylpentane & 0.96 & 0.30 & 0.33 & 0.56 & 0.57 & 0.60 \\
\hline 2-methylhexane & 0.94 & $\mathrm{Nd}$ & 1.60 & 0.62 & 0.65 & 1.04 \\
\hline heptane & 0.60 & 0.80 & 0.76 & 0.59 & 0.58 & 0.73 \\
\hline 3-methylheptane & $\mathrm{Nd}$ & $\mathrm{Nd}$ & 0.93 & 0.51 & 0.57 & 0.74 \\
\hline 2-methylheptane & 0.44 & $\mathrm{Nd}$ & 0.66 & 0.35 & 0.37 & 0.50 \\
\hline 2,3-dimethylpentane & 1.75 & $\mathrm{Nd}$ & 0.48 & 0.38 & 0.38 & 0.82 \\
\hline octane & 0.35 & 0.30 & 0.35 & 0.26 & 0.28 & 0.34 \\
\hline methylcyclohexane & 0.61 & 0.20 & 0.42 & 0.21 & 0.23 & 0.36 \\
\hline propane & 0.21 & 0.20 & 0.36 & 0.09 & 0.08 & 0.21 \\
\hline cyclohexane & 0.47 & 0.10 & 0.07 & 0.17 & 0.18 & 0.22 \\
\hline nonane & 0.14 & 0.10 & 0.22 & 0.09 & 0.10 & 0.14 \\
\hline decane & 0.10 & $\mathrm{Nd}$ & 0.18 & 0.03 & 0.03 & 0.09 \\
\hline ethene & 9.56 & 7.90 & 10.22 & 6.32 & 6.26 & 8.82 \\
\hline propene & 4.88 & 4.00 & 4.84 & 3.81 & 3.72 & 4.65 \\
\hline 1,3-butadiene & $\mathrm{Nd}$ & 0.80 & 0.96 & 0.57 & 0.41 & 0.75 \\
\hline trans-2-butene & 0.72 & 0.40 & 0.48 & 0.45 & 0.38 & 0.53 \\
\hline cis-2-butene & 0.29 & 0.30 & 0.43 & 0.32 & 0.27 & 0.36 \\
\hline trans-2-pentene & 0.23 & $\mathrm{Nd}$ & 0.47 & 0.35 & 0.33 & 0.38 \\
\hline 1-pentene & 0.13 & $\mathrm{Nd}$ & 0.30 & 0.21 & 0.20 & 0.23 \\
\hline 1-hexene & 0.14 & $\mathrm{Nd}$ & $\mathrm{Nd}$ & 0.19 & 0.19 & 0.19 \\
\hline cis-2-pentene & 0.14 & $\mathrm{Nd}$ & 0.31 & 0.19 & 0.18 & 0.23 \\
\hline isoprene & $\mathrm{Nd}$ & $\mathrm{Nd}$ & $\mathrm{Nd}$ & 0.13 & 0.13 & 0.14 \\
\hline 1-butene & $\mathrm{Nd}$ & 1.90 & 2.52 & 0.00 & 0.00 & 1.21 \\
\hline ethyne & 4.19 & 5.40 & 3.31 & 4.50 & 5.52 & 5.02 \\
\hline propyne & $\mathrm{Nd}$ & 0.30 & 0.26 & 0.00 & 0.00 & 0.15 \\
\hline toluene & 6.97 & 13.90 & 9.60 & 18.46 & 19.31 & 14.95 \\
\hline m,p-xylene & 4.68 & 7.80 & 4.78 & 8.20 & 8.67 & 7.48 \\
\hline benzene & 3.90 & 9.30 & 8.69 & 4.28 & 4.39 & 6.70 \\
\hline 1,2,4-trimethylbenzene & 1.87 & 0.90 & 3.60 & 4.59 & 4.68 & 3.43 \\
\hline ethylbenzene & 1.37 & 2.00 & 1.42 & 3.79 & 3.96 & 2.75 \\
\hline o-xylene & 1.77 & 2.60 & 2.34 & 3.28 & 3.46 & 2.95 \\
\hline propylbenzene & 0.27 & 0.30 & 0.50 & 3.10 & 3.27 & 1.63 \\
\hline 1,2,3-trimethylbenzene & $\mathrm{Nd}$ & $\mathrm{Nd}$ & 0.90 & 1.40 & 1.47 & 1.38 \\
\hline styrene & $\mathrm{Nd}$ & 0.20 & 0.41 & 0.83 & 0.77 & 0.61 \\
\hline formaldehyde & 2.84 & $\mathrm{Nd}$ & $\mathrm{Nd}$ & 3.17 & 2.04 & 2.94 \\
\hline benzaldehyde & 0.42 & $\mathrm{Nd}$ & $\mathrm{Nd}$ & 1.06 & 0.94 & 0.88 \\
\hline acetone & 0.39 & $\mathrm{Nd}$ & $\mathrm{Nd}$ & 0.12 & 0.12 & 0.23 \\
\hline butyraldehyde & $\mathrm{Nd}$ & $\mathrm{Nd}$ & $\mathrm{Nd}$ & 0.08 & 0.05 & 0.07 \\
\hline propionaldehyde & $\mathrm{Nd}$ & $\mathrm{Nd}$ & $\mathrm{Nd}$ & 0.07 & 0.05 & 0.07 \\
\hline methylethylketone & $\mathrm{Nd}$ & $\mathrm{Nd}$ & $\mathrm{Nd}$ & 0.18 & 0.14 & 0.18 \\
\hline valeraldehyde & $\mathrm{Nd}$ & $\mathrm{Nd}$ & $\mathrm{Nd}$ & 0.04 & 0.04 & 0.05 \\
\hline acrolein & $\mathrm{Nd}$ & $\mathrm{Nd}$ & $\mathrm{Nd}$ & 0.25 & 0.25 & 0.28 \\
\hline acetaldehyde & $\mathrm{Nd}$ & $\mathrm{Nd}$ & $\mathrm{Nd}$ & 0.44 & 0.38 & 0.45 \\
\hline
\end{tabular}

a referred to the warm phase measurements; ${ }^{b}$ referred to the cold start phase measurements; and Nd means not detected. 
Table 2. The identified profile (weight \%) of gasoline evaporation emission (41 species), based on a wide literature review.

\begin{tabular}{|c|c|c|c|c|c|c|c|c|}
\hline Species & $\begin{array}{l}\text { Na et } \\
\text { al. }(2004)^{\mathrm{a}}\end{array}$ & $\begin{array}{l}\text { Na et } \\
\text { al. }(2004)^{b}\end{array}$ & $\begin{array}{l}\text { Na et } \\
\text { al. }(2004)^{c}\end{array}$ & $\begin{array}{l}\text { Nelson et } \\
\text { al. (1983) }\end{array}$ & $\begin{array}{l}\text { McLaren et } \\
\text { al. (1996) }\end{array}$ & $\begin{array}{l}\text { Wadden et } \\
\text { al. (1986) }\end{array}$ & $\begin{array}{l}\text { Conner et } \\
\text { al. (1995) }\end{array}$ & $\begin{array}{l}\text { Normalized } \\
\text { averages }\end{array}$ \\
\hline ethane & 0.00 & 0.00 & 0.00 & 0.00 & $\mathrm{Nd}$ & 0.00 & 0.14 & 0.02 \\
\hline propane & 2.33 & 1.53 & 1.40 & 1.50 & $\mathrm{Nd}$ & 1.80 & 0.97 & 1.56 \\
\hline butane & 17.34 & 20.70 & 19.88 & 18.70 & 19.92 & 19.10 & 21.80 & 19.31 \\
\hline i-butane & 13.03 & 10.32 & 9.73 & 11.10 & 5.68 & 15.20 & 5.13 & 9.86 \\
\hline pentane & 8.21 & 8.27 & 8.42 & 10.70 & 12.30 & 13.10 & 7.40 & 9.61 \\
\hline i-pentane & 24.38 & 25.32 & 25.32 & 25.40 & 25.65 & 35.80 & 27.90 & 26.66 \\
\hline 2-methylpentane & 3.48 & 4.20 & 4.45 & 3.50 & 3.83 & 6.30 & 3.53 & 4.12 \\
\hline 3-methylpentane & 2.05 & 2.58 & 2.74 & 2.20 & 2.20 & 3.10 & 1.93 & 2.36 \\
\hline 2,2-dimethylbutane & 0.69 & 0.84 & 0.87 & 0.60 & 0.33 & $\mathrm{Nd}$ & 0.68 & 0.66 \\
\hline 2,3-dimethylbutane & 0.82 & 0.98 & 1.02 & 1.10 & 1.22 & $\mathrm{Nd}$ & 1.49 & 1.09 \\
\hline hexane & 1.56 & 1.99 & 2.15 & 1.90 & 2.27 & 3.20 & 1.20 & 2.01 \\
\hline 2-methylhexane & 0.65 & 1.17 & 1.31 & 0.70 & $\mathrm{Nd}$ & $\mathrm{Nd}$ & 0.46 & 0.84 \\
\hline 3-methylhexane & 0.48 & 0.89 & 1.00 & 0.50 & 0.47 & $\mathrm{Nd}$ & 0.44 & 0.62 \\
\hline 2,4-dimethylpentane & 0.18 & 0.27 & 0.27 & 0.20 & $\mathrm{Nd}$ & $\mathrm{Nd}$ & 0.52 & 0.28 \\
\hline heptane & 0.23 & 0.49 & 0.46 & 0.30 & 0.21 & $\mathrm{Nd}$ & 0.21 & 0.31 \\
\hline 2-methylheptane & 0.03 & 0.07 & 0.08 & $\mathrm{Nd}$ & 0.05 & $\mathrm{Nd}$ & 0.06 & 0.06 \\
\hline 3-methylheptane & 0.04 & 0.08 & 0.09 & $\mathrm{Nd}$ & 0.05 & $\mathrm{Nd}$ & 0.01 & 0.05 \\
\hline octane & 0.02 & 0.05 & 0.06 & 0.00 & 0.03 & $\mathrm{Nd}$ & 0.03 & 0.03 \\
\hline nonane & 0.00 & 0.00 & 0.00 & 0.00 & 0.00 & $\mathrm{Nd}$ & 0.01 & 0.00 \\
\hline ethylene & 0.00 & 0.00 & 0.00 & 0.00 & $\mathrm{Nd}$ & $\mathrm{Nd}$ & 0.01 & 0.00 \\
\hline propylene & 0.00 & 0.00 & 0.00 & 0.00 & $\mathrm{Nd}$ & $\mathrm{Nd}$ & 0.13 & 0.03 \\
\hline 1-butene & 2.05 & 1.19 & 0.92 & 1.60 & $\mathrm{Nd}$ & $\mathrm{Nd}$ & 0.98 & 1.33 \\
\hline trans-2-butene & 5.80 & 3.06 & 4.12 & 3.70 & $\mathrm{Nd}$ & $\mathrm{Nd}$ & 1.54 & 3.58 \\
\hline cis-2-butene & 4.49 & 2.78 & 2.99 & 2.90 & $\mathrm{Nd}$ & $\mathrm{Nd}$ & 1.38 & 2.86 \\
\hline 1-pentene & 1.37 & 1.39 & 1.32 & 0.70 & $\mathrm{Nd}$ & $\mathrm{Nd}$ & 1.19 & 1.17 \\
\hline isoprene & 0.00 & 0.00 & 0.00 & 1.50 & $\mathrm{Nd}$ & $\mathrm{Nd}$ & 0.07 & 0.31 \\
\hline trans-2-pentene & 2.76 & 2.83 & 2.73 & $\mathrm{Nd}$ & $\mathrm{Nd}$ & $\mathrm{Nd}$ & 2.29 & 2.61 \\
\hline cis-2-pentene & 1.44 & 1.51 & 1.46 & 0.90 & $\mathrm{Nd}$ & $\mathrm{Nd}$ & 1.25 & 1.29 \\
\hline 2-methyl-2-butene & 3.61 & 4.08 & 3.94 & 2.60 & $\mathrm{Nd}$ & $\mathrm{Nd}$ & 2.88 & 3.37 \\
\hline ethyne & 0.00 & 0.00 & 0.00 & 0.00 & $\mathrm{Nd}$ & $\mathrm{Nd}$ & 0.01 & 0.00 \\
\hline cyclopentane & 0.62 & 0.39 & 0.42 & 0.60 & 0.72 & $\mathrm{Nd}$ & 1.49 & 0.70 \\
\hline methylcyclopentane & 0.85 & 0.94 & 0.95 & 0.90 & $\mathrm{Nd}$ & $\mathrm{Nd}$ & 0.81 & 0.88 \\
\hline cyclohexane & 0.10 & 0.08 & 0.09 & 0.30 & $\mathrm{Nd}$ & $\mathrm{Nd}$ & 0.12 & 0.14 \\
\hline methylcyclohexane & 0.10 & 0.15 & 0.15 & 0.20 & 0.13 & $\mathrm{Nd}$ & 0.12 & 0.14 \\
\hline benzene & 0.57 & 0.59 & 0.51 & 0.90 & 0.93 & 0.90 & 0.86 & 0.74 \\
\hline toluene & 0.62 & 0.96 & 0.93 & 1.00 & 1.27 & 1.00 & 1.26 & 0.99 \\
\hline ethylbenzene & 0.02 & 0.04 & 0.04 & 0.10 & 0.07 & 0.10 & 0.11 & 0.07 \\
\hline m,p-xylene & 0.06 & 0.13 & 0.12 & 0.20 & 0.27 & 0.30 & 0.32 & 0.20 \\
\hline o-xylene & 0.02 & 0.05 & 0.05 & 0.10 & 0.08 & 0.10 & 0.12 & 0.07 \\
\hline styrene & 0.00 & 0.00 & 0.00 & 0.00 & $\mathrm{Nd}$ & $\mathrm{Nd}$ & 0.10 & 0.02 \\
\hline 1,2,4-trimethylbenzene & 0.01 & 0.05 & 0.06 & 0.00 & $\mathrm{Nd}$ & $\mathrm{Nd}$ & 0.11 & 0.05 \\
\hline
\end{tabular}

${ }^{\mathrm{a}}$ referred to measurements conducted in Spring; ${ }^{\mathrm{b}}$ referred to measurements conducted in Summer; ${ }^{\mathrm{c}}$ referred to measurements conducted in Winter; and Nd means not detected.

and non-TWC gasoline vehicles were running, the utilization rate of TWC by gasoline vehicles in each province for a specific year can be calculated based on the cumulative population of newly-used gasoline vehicles in each province since 2000 and the total provincial gasoline vehicle population in that year by referring to the governmental statistical data (NBS, 2006). Thus, the identified emission profile for gasoline vehicles with TWC was applied to provincial emissions of all newly-used gasoline vehicles since 2000, and the emission profile for gasoline vehicles without TWC was applied to emissions of all gasoline vehicles for the period of 1980-1995.

\subsection{Emission allocation}

In order to understand the spatial distribution of NMVOC species, and to aid model simulation and evaluation of the effects of reactive and toxic species on human health and air quality, emissions of alkenes, aromatics and carbonyls in China were gridded at a resolution of $40 \mathrm{~km} \times 40 \mathrm{~km}$ using Arcgis, a GIS software. Firstly, provincial emissions were allocated to the county-level, emissions, following a top-down approach based on a proxy variable of GDP, using 
Eq. (3):

$E_{m, n}=\frac{G_{n}}{G_{m}} \times E_{m}$

Where $E_{m, n}$ is the emission in county $n$ of province $m ; E_{m}$ is the emission in province $m ; G_{n}$ and $G_{m}$ are the GDP in county $n$ and province $m$, respectively.

Secondly, the latitude and longitude projected map of China was gridded at a resolution of $40 \mathrm{~km} \times 40 \mathrm{~km}$ using Arcgis, which further calculated the ratios of the areas of each county that fell over various grid cells to the area of that county. Then, the emission of that county was allocated to each covering grid cell based on the calculated ratios. Finally, the emission within a grid cell was the sum of the emissions from the covered areas of various adjacent counties.

In comparison with the alternative option for spatial allocation of emissions based on some geographical variables like road network or street density (Tuia et al., 2007; Ossés et al., 2008; Zheng et al., 2009), which could generate more accurate emission inventory at the city-level application when the geographical variable data were available, the major limitation of the spatial allocation based on the factor of GDP as we did was that our GDP-based top-down allocation approach assumes that the traffic emission is homogenously distributed over every entire city, neglecting spatial variation of emissions within cities. To assure the consistency and comparability of the time-series results and meantime keep the possible inaccuracy to an acceptable level, we gave up the road network-based method to avoid possibly larger uncertainty and inaccuracy due to serious lack of data, particularly in the earlier period, than the GDP-based method, which we finally adopted based on the proved strong correlation between emissions and GDP. While our results can provide an approximation to the real-world situation on a county scale, higher spatial accuracy requires the application of the bottom-up approach based on the availability of accurate local data such as detailed road network, traffic volume on specific road segments or street densities. Therefore, prospective users of the emission inventories, who need higher spatial resolution and accuracy at a county or provincial level, can further allocate our inventories based on the local geographical variables (e.g. road networks) when these data are available, in order to satisfy their practical needs.

\section{Results and discussion}

\subsection{Temporal variation of emissions and emission contributions of vehicle categories from 1980 to 2005}

\subsubsection{Temporal variation of emissions}

Over the past two and half decades, China has experienced fast economic growth, together with a rapid increase of motor vehicle population by 60 times, from 1.8 million in 1980 to 107 million in 2005 (Cai and Xie, 2007). Meanwhile, the annual NMVOC emissions in China had increased exponentially by 35 times at an annual average rate of $15 \%$, from 171.1 thousand tons in 1980 to 5958.8 thousand tons in 2005. The direct cause for this emission increase must be ascribed to the substantial growth of vehicle population, increase of the vehicle miles travelled (VMT) (He, 1999; Hu et al., 2002; Li et al., 2003; Zhang et al., 2004; Ye et al., 2007; Fu et al., 2008; Yu and Yu., 2008), and the late execution of more stringent fuel and emission standards in China over the past few decades.

Multi-year vehicular emissions of sixty-seven NMVOC species, including alkanes, alkenes, alkines, aromatics and carbonyls, are shown in Table 3, which reveals that emissions of all groups experienced exponential increase during the period of 1980-2005: emissions of alkanes, alkenes, alkines, aromatics and carbonyls had increased by about $43,32,26$, 37 and 17 times, respectively, during the period. Besides, emissions from tailpipe exhaust and emissions from fuel evaporation increased from 143.4 and 27.7 thousand tons, respectively, in 1980 to 4817.7 and 1141.1 thousand tons, respectively, in 2005. Despite the introduction of Euro I and Euro II regulations in recent years, the decrease of emission factors for individual vehicles has yet to change the exponentially increasing trend of emissions, due to the rapid growth of vehicle population throughout the country. Meanwhile, proportion of evaporation emissions grew from $16.2 \%$ in 2000 to $19.1 \%$ in 2005 , showing an increasing trend in recent years. The major cause for this increase was the rapid growth of motorcycle population for the period of 20002005, despite the emission standard updates of motorcycles: emission factors of motorcycles in China were high and had no control measures for fuel evaporation emission, resulting in huge quantities of NMVOC emissions due to evaporation (Chan, 2002; Tsai, 2006; MEP, 2007). This situation stayed unimproved until stricter emission standards for motorcycles came into force in 2007, when the limit for evaporation had a definite value of $2 \mathrm{~g} / \mathrm{km}$, and the limits for exhaust emissions were 0.8 and $0.3 \mathrm{~g} / \mathrm{km}$ for motorcycles with cylinder capacities not exceeding $150 \mathrm{~mL}$ and those exceeding $150 \mathrm{~mL}$, respectively (MEP and GAQSIQ, 2007a, b), in comparison with the previously prescribed limits for exhaust emissions of as high as $4 \mathrm{~g} / \mathrm{km}$ for two-stroke motorcycles and $3 \mathrm{~g} / \mathrm{km}$ for four-stroke motorcycles, which came into force in 2000 (MEP and GAQSIQ, 2000), when there was no control standard for evaporation emissions. Therefore, the emission standard updates for motorcycles revealed that, for motorcycles, the evaporation emission factor was always higher than the exhaust emission factor, leading to more evaporation emissions than exhaust emissions from motorcycles and thus the increase of the proportion of evaporation emissions of motorcycles. Finally, the increase of the proportion of evaporation emissions of the whole vehicle fleet was driven by the ever growing population of motorcycles producing more evaporation emissions. Thus, even stricter control of evaporative NMVOC emissions from motorcycles is required to 
Table 3. Emissions (thousand tons) of speciated NMVOC groups (alkanes, alkenes and alkines, aromatics and carbonyls) from 1980 to 2005.

\begin{tabular}{|c|c|c|c|c|c|c|c|c|c|c|}
\hline NMVOC Species & 1980 & 1985 & 1990 & 1995 & 2000 & 2001 & 2002 & 2003 & 2004 & 2005 \\
\hline propane & 0.9 & 1.8 & 5.9 & 16.3 & 21.9 & 25.7 & 27.6 & 31.7 & 40.1 & 43.8 \\
\hline pentane & 8.2 & 17.4 & 50.9 & 146.1 & 208.5 & 243.3 & 253.5 & 292.5 & 365.5 & 390.4 \\
\hline octane & 0.7 & 1.6 & 3.8 & 11.5 & 16.4 & 19.1 & 19.5 & 22.7 & 27.5 & 28.9 \\
\hline nonane & 1.2 & 2.3 & 3.9 & 9.9 & 13.9 & 15.9 & 17.0 & 19.3 & 22.0 & 23.6 \\
\hline methylcyclopentane & 0.2 & 0.5 & 1.7 & 4.5 & 5.8 & 6.7 & 7.6 & 8.6 & 11.2 & 12.8 \\
\hline methylcyclohexane & 0.6 & 1.3 & 3.4 & 9.8 & 13.2 & 15.3 & 15.7 & 18.2 & 21.9 & 23.5 \\
\hline isopentane & 10.9 & 23.0 & 59.7 & 175.1 & 239.6 & 275.8 & 278.9 & 322.0 & 383.1 & 407.0 \\
\hline isooctane & 1.1 & 2.3 & 6.7 & 19.3 & 22.8 & 26.2 & 27.3 & 31.4 & 36.3 & 41.9 \\
\hline isobutane & 0.3 & 0.8 & 2.1 & 6.5 & 11.7 & 14.5 & 15.3 & 18.6 & 23.7 & 25.5 \\
\hline hexane & 2.3 & 4.8 & 13.9 & 40.5 & 57.4 & 67.1 & 69.8 & 80.9 & 100.3 & 107.9 \\
\hline heptane & 1.1 & 2.4 & 6.6 & 19.5 & 28.9 & 33.9 & 34.7 & 40.6 & 49.9 & 52.9 \\
\hline ethane & 1.9 & 3.8 & 9.0 & 24.7 & 30.5 & 35.3 & 38.1 & 44.0 & 50.6 & 59.2 \\
\hline decane & 1.8 & 3.5 & 5.3 & 12.4 & 17.8 & 20.0 & 21.9 & 24.3 & 27.1 & 29.3 \\
\hline cyclopentane & 0.2 & 0.4 & 1.3 & 3.4 & 4.4 & 5.1 & 5.8 & 6.6 & 8.6 & 9.8 \\
\hline cyclohexane & 0.5 & 1.0 & 2.8 & 8.1 & 10.8 & 12.5 & 12.7 & 14.6 & 17.5 & 18.6 \\
\hline butane & 7.0 & 13.6 & 45.1 & 120.7 & 160.6 & 187.4 & 207.6 & 235.0 & 303.1 & 339.5 \\
\hline 3-methylpentane & 2.4 & 5.1 & 15.0 & 43.1 & 60.3 & 70.5 & 74.0 & 85.7 & 106.1 & 115.5 \\
\hline 3-methylhexane & 1.4 & 3.0 & 8.2 & 23.8 & 33.0 & 38.3 & 39.4 & 45.5 & 55.3 & 59.3 \\
\hline 3-methylheptane & 0.7 & 1.6 & 4.3 & 13.2 & 20.8 & 24.8 & 25.5 & 30.3 & 37.5 & 39.8 \\
\hline 2-methylpentane & 4.2 & 8.7 & 24.6 & 70.3 & 98.6 & 115.3 & 121.5 & 140.5 & 174.1 & 189.6 \\
\hline 2-methylhexane & 1.5 & 3.1 & 8.5 & 24.9 & 35.8 & 41.9 & 43.5 & 50.7 & 62.4 & 67.0 \\
\hline 2-methylheptane & 0.5 & 1.1 & 2.8 & 8.6 & 15.5 & 18.8 & 19.5 & 23.5 & 29.7 & 31.3 \\
\hline 2,4-dimethylpentane & 0.7 & 1.5 & 4.2 & 12.2 & 14.9 & 17.0 & 17.5 & 19.9 & 23.5 & 26.0 \\
\hline 2,3-dimethylpentane & 1.0 & 2.1 & 5.4 & 15.3 & 18.9 & 21.3 & 21.9 & 24.8 & 28.4 & 31.6 \\
\hline 2,3-dimethylbutane & 1.4 & 2.9 & 8.1 & 22.8 & 32.0 & 38.1 & 41.3 & 48.4 & 59.6 & 67.6 \\
\hline 2,2-dimethylbutane & 0.9 & 1.8 & 7.2 & 18.7 & 16.2 & 18.3 & 19.3 & 21.6 & 25.2 & 28.4 \\
\hline i-pentane & 7.4 & 13.9 & 48.8 & 126.6 & 166.4 & 194.6 & 221.1 & 248.4 & 327.6 & 370.6 \\
\hline i-butane & 2.7 & 5.1 & 18.0 & 46.8 & 61.5 & 72.0 & 81.8 & 91.9 & 121.2 & 137.1 \\
\hline trans-2-pentene & 1.4 & 3.0 & 8.9 & 24.9 & 36.0 & 42.3 & 45.2 & 52.1 & 66.3 & 71.9 \\
\hline trans-2-butene & 1.6 & 3.1 & 9.3 & 24.9 & 33.9 & 39.7 & 44.0 & 50.1 & 64.1 & 71.7 \\
\hline propene & 7.7 & 15.0 & 28.3 & 72.9 & 98.8 & 113.7 & 123.4 & 140.9 & 161.5 & 181.7 \\
\hline isoprene & 0.2 & 0.3 & 0.9 & 2.4 & 3.4 & 4.1 & 4.7 & 5.4 & 6.9 & 7.8 \\
\hline ethene & 17.5 & 34.1 & 61.9 & 156.7 & 219.0 & 252.4 & 274.6 & 313.6 & 360.1 & 401.6 \\
\hline cyclopentene & 0.0 & 0.0 & 0.02 & 0.1 & 0.1 & 0.1 & 0.1 & 0.1 & 0.1 & 0.1 \\
\hline cis-3-heptene & 0.7 & 1.9 & 4.9 & 15.6 & 28.1 & 33.5 & 33.5 & 40.0 & 50.7 & 50.8 \\
\hline cis-2-pentene & 0.8 & 1.6 & 4.6 & 13.0 & 18.9 & 22.2 & 23.7 & 27.4 & 34.8 & 37.7 \\
\hline cis-2-butene & 1.2 & 2.4 & 7.3 & 19.4 & 26.7 & 31.3 & 34.6 & 39.4 & 50.6 & 56.5 \\
\hline 3-methyl-1-butene & 0.0 & 0.0 & 0.03 & 0.1 & 0.1 & 0.1 & 0.1 & 0.1 & 0.2 & 0.2 \\
\hline 2-methyl-1-butene & 0.6 & 1.6 & 4.4 & 13.9 & 24.7 & 29.4 & 29.4 & 35.1 & 44.4 & 44.6 \\
\hline 2-methyl-2-butene & 2.7 & 6.3 & 18.4 & 54.9 & 90.4 & 107.5 & 110.8 & 130.1 & 166.5 & 172.4 \\
\hline 1-pentene & 1.4 & 2.8 & 6.1 & 16.0 & 22.4 & 25.9 & 28.0 & 31.8 & 38.7 & 42.3 \\
\hline 1-hexene & 0.8 & 1.6 & 2.5 & 5.8 & 8.0 & 9.0 & 10.0 & 11.1 & 12.3 & 13.7 \\
\hline 1-butene & 1.8 & 3.7 & 9.1 & 24.9 & 35.0 & 41.0 & 44.1 & 50.8 & 62.1 & 68.7 \\
\hline 1,3-butadiene & 0.8 & 1.6 & 3.4 & 9.1 & 12.1 & 14.0 & 15.1 & 17.4 & 20.0 & 22.8 \\
\hline ethyne & 6.6 & 13.0 & 27.6 & 73.7 & 94.8 & 108.5 & 115.8 & 132.1 & 151.3 & 170.7 \\
\hline propyne & 0.3 & 0.5 & 1.2 & 3.4 & 4.6 & 5.2 & 5.4 & 6.2 & 7.3 & 7.9 \\
\hline toluene & 10.3 & 21.2 & 58.6 & 170.0 & 220.8 & 257.4 & 270.1 & 314.4 & 373.2 & 421.2 \\
\hline styrene & 0.6 & 1.2 & 3.0 & 8.0 & 9.3 & 10.5 & 11.2 & 12.7 & 14.2 & 16.5 \\
\hline propylbenzene & 1.2 & 2.3 & 5.9 & 16.8 & 20.2 & 23.2 & 24.6 & 28.3 & 32.6 & 37.7 \\
\hline o-xylene & 2.3 & 4.8 & 12.8 & 37.0 & 48.5 & 56.4 & 58.8 & 68.4 & 81.0 & 90.5 \\
\hline o-ethyltoluene & 0.4 & 0.7 & 1.2 & 2.8 & 3.8 & 4.2 & 4.7 & 5.2 & 5.7 & 6.2 \\
\hline $\mathrm{m}, \mathrm{p}$-xylene & 6.1 & 12.7 & 34.7 & 100.8 & 131.8 & 152.9 & 158.6 & 184.0 & 217.8 & 242.1 \\
\hline m,p-ethyltoluene & 2.8 & 5.8 & 11.4 & 31.3 & 50.7 & 59.2 & 61.2 & 71.1 & 85.9 & 88.6 \\
\hline ethylbenzene & 2.0 & 4.1 & 11.0 & 31.8 & 41.3 & 48.1 & 50.4 & 58.6 & 69.3 & 78.0 \\
\hline benzene & 6.8 & 13.5 & 31.7 & 86.8 & 110.5 & 127.3 & 136.1 & 156.1 & 181.2 & 206.4 \\
\hline 1,3,5-trimethylbenzene & 0.4 & 1.0 & 2.9 & 9.3 & 17.6 & 22.0 & 23.7 & 29.1 & 37.2 & 40.9 \\
\hline 1,2,4-trimethylbenzene & 3.3 & 6.7 & 15.9 & 44.4 & 57.5 & 66.5 & 70.2 & 80.9 & 94.3 & 106.2 \\
\hline 1,2,3-trimethylbenzene & 0.6 & 1.2 & 2.3 & 6.2 & 9.8 & 11.4 & 11.8 & 13.7 & 16.4 & 17.0 \\
\hline valeraldehyde & 0.6 & 1.1 & 1.5 & 3.5 & 5.1 & 5.7 & 6.4 & 7.1 & 7.9 & 8.6 \\
\hline propionaldehyde & 0.9 & 1.7 & 2.4 & 5.6 & 11.7 & 13.2 & 14.6 & 16.3 & 18.0 & 19.6 \\
\hline methylethylketone & 0.02 & 0.04 & 0.1 & 0.3 & 0.8 & 1.1 & 1.3 & 1.6 & 2.1 & 2.5 \\
\hline formaldehyde & 14.1 & 26.9 & 48.5 & 120.1 & 144.8 & 160.1 & 171.2 & 188.5 & 204.6 & 226.7 \\
\hline butyraldehyde & 0.5 & 0.9 & 1.3 & 3.0 & 4.3 & 4.9 & 5.5 & 6.2 & 6.9 & 7.6 \\
\hline benzaldehyde & 1.2 & 2.4 & 5.7 & 15.4 & 17.3 & 19.2 & 19.9 & 22.2 & 24.4 & 27.8 \\
\hline acrolein & 1.0 & 1.9 & 3.4 & 8.4 & 10.8 & 12.1 & 13.1 & 14.6 & 16.1 & 17.9 \\
\hline acetone & 1.4 & 2.6 & 4.6 & 11.1 & 14.3 & 15.8 & 17.2 & 18.9 & 20.6 & 22.8 \\
\hline acetaldehyde & 4.6 & 8.7 & 14.4 & 34.4 & 45.4 & 50.5 & 54.9 & 60.5 & 66.1 & 72.4 \\
\hline Sum of Alkanes & 63.9 & 130.3 & 377.5 & 1054.3 & 1438.1 & 1674.7 & 1779.3 & 2042.0 & 2539.0 & 2778.2 \\
\hline Sum of Alkenes & 39.3 & 78.9 & 170.1 & 454.5 & 657.4 & 766.2 & 821.3 & 945.5 & 1139.3 & 1244.5 \\
\hline Sum of Alkines & 6.9 & 13.5 & 28.8 & 77.0 & 99.3 & 113.7 & 121.3 & 138.4 & 158.6 & 178.7 \\
\hline Sum of Aromatics & 36.8 & 75.2 & 191.5 & 545.1 & 721.9 & 839.3 & 881.4 & 1022.4 & 1208.6 & 1351.4 \\
\hline Sum of Carbonyls & 24.1 & 46.2 & 81.9 & 201.9 & 254.4 & 282.7 & 304.0 & 335.8 & 366.7 & 406.0 \\
\hline Total NMVOC Emission & 171.1 & 344.1 & 849.8 & 2332.8 & 3171.2 & 3676.6 & 3907.3 & 4484.1 & 5412.1 & 5958.8 \\
\hline
\end{tabular}


slow down the increasing trend of evaporative emissions and bring down the total emissions.

Statistical analysis of the relationship between NMVOC emissions and economic growth showed that China's economic growth had a well positive correlation with the tremendous increase of total, total tailpipe exhaust and total evaporation emissions of NMVOC over the period of 1980 2005, with a correlation coefficient of 0.99 at the significant level of 0.01 between the GDP growth and total NMVOC emission increase, as shown by Fig. 1.

Figure 1 depicts clearly that economic growth has been a powerful driving force for vehicular NMVOC emissions. With the persistent and rapid growth of income of residents, Chinese people's capabilities and desires of owning a private car have been unprecedentedly strong, which guaranteed the continuous growth of vehicle population in China and thus the enormous increase of vehicular NMVOC emissions.

\subsubsection{Annual emission contributions of various vehicle categories}

Although it has been recognized that light duty vehicles (LDV) and heavy duty vehicles (HDV) were the primary contributors to total NMVOC emissions in the 1980s, and motorcycles dominated in the total emission contribution for the period of 1990-2005 (Cai and Xie, 2007), contributions of vehicle categories to the emissions of speciated NMVOC groups varied, due to the variance in the gross NMVOC emission quantities and the accordingly adopted emission profiles for different vehicle categories. Contributions of vehicle categories to emissions of speciated NMVOC groups for the period of 1980-2005 are depicted in Fig. 2, to provide the policy-makers with evidences of primary contributors to specific NMVOC groups when designing cost-effective measures for the reduction and control of both total and speciated NMVOC emissions.

Figure 2a shows that contributions of vehicle categories to alkane emissions varied with time. Motorcycles, commonly used in cities in the 1980s and became popular later in rural areas of China, were the primary contributors during the period of 1980-2005, due to their relatively higher emission factors and their huge and ceaselessly growing population. Passenger cars (PC), due to their large and increasing population and poor levels of emission control, were another major contributors. LDV, due to their wide utilization in freight transportation in the 1980 s, were also major contributors then. However, their contribution decreased later on, due to their slower increase of population in comparison with other vehicle categories. HDV and buses, due to their relatively small population, contributed less than $1 \%$ in the 1980 s, about $4-5 \%$ in the 1990 s and about $3 \%$ for the period of 2000-2005. Therefore, motorcycles and PC were responsible for most alkane emissions, altogether accounting for $79 \%, 90 \%$ and 93\%, respectively, in 1985, 1995 and 2005. Besides, provincial differences of vehicle category contribu-

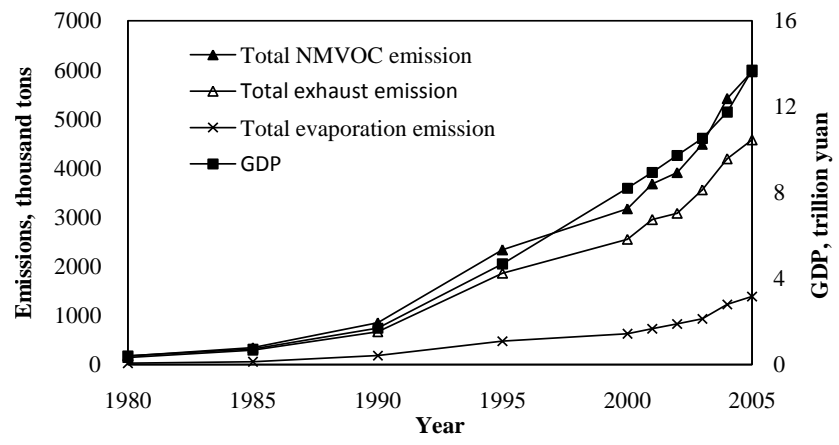

Fig. 1. Exponential increase of vehicular emissions of total NMVOC, including tailpipe exhaust emissions and evaporation emissions from 1980 to 2005, in comparison with China's economic growth during the period.

tion were significant, mainly due to diverse compositions of provincial vehicle fleet. For example, PC were the primary contributors in Beijing, accounting for $67-82 \%$ of alkane emissions during the period of 2000-2005, when motorcycles, however, were the major contributors in Guangdong, responsible for $74-78 \%$ of the emissions. Therefore, measures to control and reduce provincial emissions should be established and taken individually according to the specific major contributors in each province.

As shown in Fig. 2b, motorcycles and PC, due to their massive population and high VMT, were the major contributors to alkene and alkine emissions during the period of 1980-2005. In the 1980s, motorcycles contributed 50-59\% to the total emissions, followed by PC and LDV, which accounted for $19-23 \%$ and $17-20 \%$, respectively. In the 1990 s, contribution of HDV mainly burning diesel increased significantly and accounted for about 23-28\%, while motorcycles and PC still dominated in the emission share in that period. Due to their huge population and high emission factors, motorcycles continued to dominate in the emission contributions for the period of 2000-2005, followed by HDV and PC, which accounted for $17-20 \%$ and $15-17 \%$, respectively. Buses contributed more during this period, due to their growing population stimulated by the increase of demand for public transportation in China's urban areas. Therefore, stringent control on motorcycles and PC is required to reduce the emissions of alkenes and alkines.

Figure $2 \mathrm{c}$ illustrates that motorcycles and PC mainly burning gasoline were the dominant contributors to aromatic emissions during the period of 1980-2005, due to their high emission factors of aromatics and much larger populations. This characteristic agreed with the result that gasoline-power vehicles were the main source of aromatic hydrocarbons (Mugica et al., 2003). Moreover, motorcycles were responsible for about $53-61 \%, 53-57 \%$ and $69-75 \%$ of aromatic emissions in the 1980s, in the 1990s and during the period of 2000-2005, respectively, showing an increasing trend in their contribution to aromatic emissions, while PC accounted 

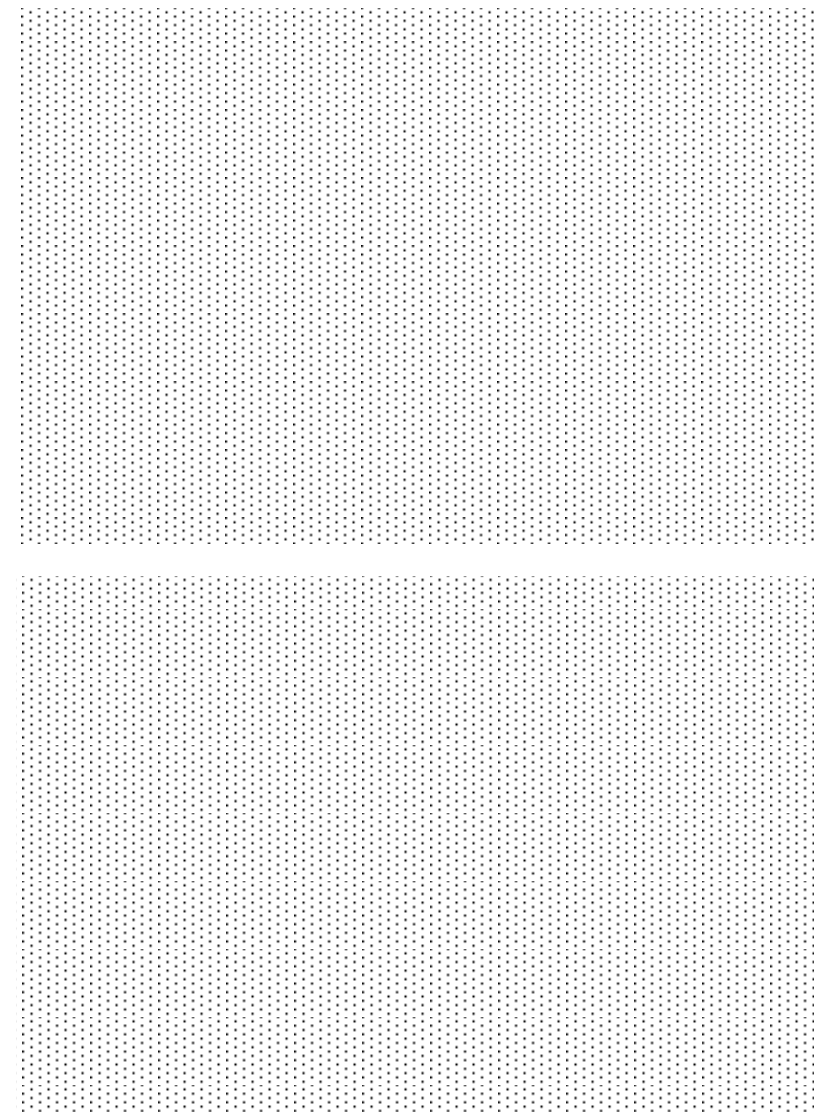
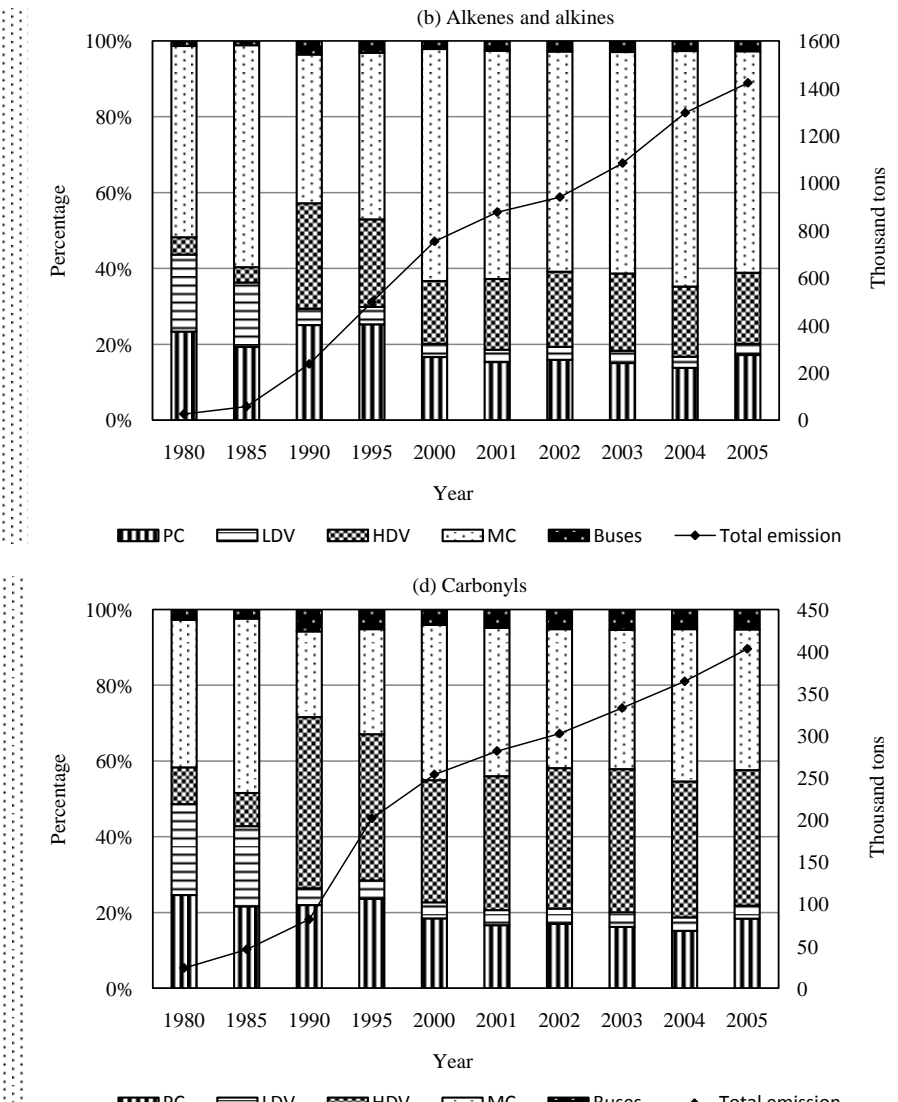

Fig. 2. Annual contributions of vehicle categories to emissions of speciated NMVOC groups (alkanes, alkenes and alkines, aromatics and carbonyls) during the period of 1980-2005. PC: passenger cars; LDV: light duty vehicles; HDV: heavy duty vehicles; MC: motorcycles.

for about $19-23 \%, 30-32 \%$ and $17-21 \%$, respectively, during the same periods, when LDV contributed about $19-22 \%$, $5-6 \% \%$ and $4-5 \%$, respectively, showing a decreasing trend in their contribution to aromatic emissions. HDV and buses, which mainly burned diesel and had relatively much smaller populations, accounted for only about $1-2 \%$ in the $1980 \mathrm{~s}$, for about $7-10 \%$ in the 1990 s and for about $5 \%$ during the period of 2000-2005.

Contributions of vehicle categories to carbonyl emissions were significantly different from those to alkane or alkene emissions, since various vehicle categories had remarkably different emission factors for carbonyl compounds and for other speciated NMVOC groups. Figure $2 d$ shows that HDV with higher emission factors for carbonyls were the major contributors during the period of 1990-2005, responsible for about 39\%, 32\% and 36\% of carbonyl emissions in 1995, 2000 and 2005, respectively, when PC, despite their much larger population, accounted for only about $24 \%, 19 \%$ and $18 \%$, respectively, for the same years. Motorcycles, due to their tremendous population, were another major contributors, accounting for about $39-46 \%, 23-28 \%$ and $39-41 \%$ in the 1980s, in the 1990s and during the period of 2000-2005, respectively.
The terms of PC, LDV, HDV, Buses and Motorcycles mentioned in the above discussion were vehicle categories defined by COPERT (Ntzaichristos and Samaras, 2000), and we have converted the vehicle categories defined by Chinese regulations to these COPERT categories when we used COPERT to calculate the emission factors of various categories (Cai and Xie, 2007). The details can be referred to the established methodology (Cai and Xie, 2007) to avoid any misunderstanding with other definitions.

\subsection{Emissions in 2005}

\subsubsection{National and provincial emissions of speciated NMVOC groups}

The emissions of alkanes, alkenes, alkines, aromatics and carbonyls in 2005 were $2778.2,1244.5,178.7,1351.4$ and 406.0 thousand tons, respectively. Alkanes, aromatics and alkenes were the dominant speciated groups, which accounted for $46.6 \%, 22.7 \%$ and $20.9 \%$, respectively.

It appears that China's vehicular NMVOC emission in 2005 was very close to that in the United States for the years of 1990-1994 (5507-5894 thousand tons, USEPA, 2008). 
There were significant differences, however, in emission densities normalized to population and in emission intensities normalized to gross domestic production (GDP, in current price): emission densities in China and the Unites States in 2005 were about $4.59 \times 10^{-3}$ and about $1.24 \times 10^{-2}$ ton per capita, respectively; emission intensities in China and the Unites States in 2005 were about $2.66 \times 10^{-3}$ and about $3.34 \times 10^{-4}$ ton $/ 10^{3}$ US dollars, respectively. Differences in emission densities revealed that the emission per capita in China in 2005 was only about $37 \%$ of that in the USA in the same year, due to the much larger population of China. Emission intensity in China in 2005, however, was about eight times higher than that of the USA in 2005, which revealed that the NMVOC emission per unit of output was much higher in China, mostly due to higher emission factors of vehicles in China. Therefore, one key measure to maintain the economic growth and meantime slow down the increase of NMVOC emissions in China should be promoting faster implementation of stricter emission regulations that allow lower emission factors, so that the NMVOC emission per unit of output in China would decrease.

Emissions of speciated NMVOC groups varied notably among provinces in China, due to remarkable differences in provincial vehicle population and composition. Figure 3, which illustrates the provincial emissions and relative proportions of speciated NMVOC groups in 2005, showed that Guangdong emitted about 821.0 thousand tons of NMVOC and ranked No. 1 among all provinces in 2005, with the emissions of alkanes, alkenes, alkines, aromatics and carbonyls accounting for 448.9, 164.5, 18.1, 152.7 and 36.7 thousand tons, respectively. Guangdong, Shandong, Jiangsu, Henan and Zhejiang, the developed regions constituting $41.0 \%$ of the total GDP but covering only $6.9 \%$ of the territory, contributed $47.2 \%, 45.5 \%, 44.4 \%, 46.9 \%$ and $40.0 \%$ of the emissions of alkanes, alkenes, alkines, aromatics and carbonyls, respectively, in 2005 . On the contrary, Tibet produced least emissions, with about 2.9, 2.4, 0.4, 2.0 and 1.6 thousand tons of alkanes, alkenes, alkines, aromatics and carbonyls, respectively, in 2005. Only $3.4 \%, 4.0 \%, 4.1 \%$, $4.0 \%$ and $4.6 \%$ of the speciated emissions, respectively, were ascribed to Tibet, Qinghai, Ningxia, Gansu and Xinjiang, five northwestern provinces covering $42.5 \%$ of the territory. Annual provincial emissions of speciated NMVOC groups from 1980 to 2005 are provided in the Supplementary Material (see http://www.atmos-chem-phys.net/9/6983/ 2009/acp-9-6983-2009-supplement.zip).

Relative emission proportions of speciated NMVOC groups at the provincial level also varied, as shown by Fig. 3, due to diverse provincial vehicle compositions which resulted in different quantities of gross NMVOC emissions and different proportions of the seven emission profiles adopted at the provincial level. In 2005, provincial ratios of alkane emissions decreased from $56.9 \%$ in Hainan, a coastal province in southern China, to $30.9 \%$ in Tibet located in northwestern China, and the provincial emission ratios of alkenes, alkines, aromatics and carbonyls decreased from $25.9 \%$ in Tibet, $4.6 \%$ in Tibet, $33.3 \%$ in Beijing and $16.7 \%$ in Tibet, respectively, to $18.9 \%$ in Beijing, $2.0 \%$ in Guangxi, $17.5 \%$ in Hainan, and $3.3 \%$ in Guangxi, respectively.

\subsubsection{Compositional characteristics of national and provincial emissions of speciated NMVOC groups}

Knowledge of compositional characteristics of speciated NMVOC groups is necessary for photochemical modeling calculations and for the design of ozone abatement strategies, as well as for the control of the concentrations of toxic air contaminants. Therefore, the compositions of speciated NMVOC groups were decoded, and typical compositional characteristics of the national emissions of speciated groups are presented in Fig. 4, which depicts the proportions of specific constituents among the corresponding groups at the national level in 2005.

Emission fractions of twenty-eight alkanes were estimated, as shown by Fig. 4a. The dominant constituents of alkanes in 2005 were isopentane, pentane, i-pentane and butane, the emissions of which accounted for about 407.0, $390.4,370.6$ and 339.5 thousand tons, respectively, followed by 2-methylpentane, i-butane, 3-methylpentane, hexane, 2,3dimethylbutane, 2-methylhexane, 3-methylhexane, ethane, heptane, propane and isooctane. The emission of these fifteen abundant constituents was about 2449.3 thousand tons in 2005 , accounting for $88.2 \%$ of the total alkane emission, and the remaining constituents of 2,2-dimethylbutane, 2methylheptane, 2,3-dimethylpentane, octane, decane, isobutane, 2,4-dimethylpentane, nonane, methylcyclohexane, cyclohexane, methylcyclopentane and cyclopentane were responsible for only $11.8 \%$ of the total.

Alkenes, due to their high photochemical reactivities (Velasco et al., 2007), were crucial for ozone production. Emission fractions of sixteen alkenes and two alkines were estimated, as shown by Fig. 4b. Ethene, propene, 2-methyl2-butene and ethyne were the most abundant constituents, the emissions of which were about 401.6, 181.7, 172.4 and 170.7 thousand tons, respectively, accounting for $65.1 \%$ of the total. The constituents of trans-2-pentene, trans2-butene, 1-butene, cis-2-butene, cis-3-heptene, 2-methyl1-butene, 1-pentene, cis-2-pentene, 1,3-butadiene and 1hexene were responsible for $32.8 \%$ of the total, with 1 hexene, propyne, isoprene, 3-methyl-1-butene and cyclopentene giving a minor contribution of $2.1 \%$ to the total emissions. High level of highly reactive compounds with large ozone-forming potentials was a distinguishable feature of China's alkene and alkine emissions, since ethene, propene, 1,3-butadiene, trans-2-butene, trans-2-pentene and 1-butene, six highly reactive compounds known to have high absolute and incremental reactivities of ozone production in the polluted atmosphere (Hurley et al., 1998), accounted for as high as $57.6 \%$ of the total alkene and alkine emission in 2005. Therefore, it is necessary to promote smarter, more 


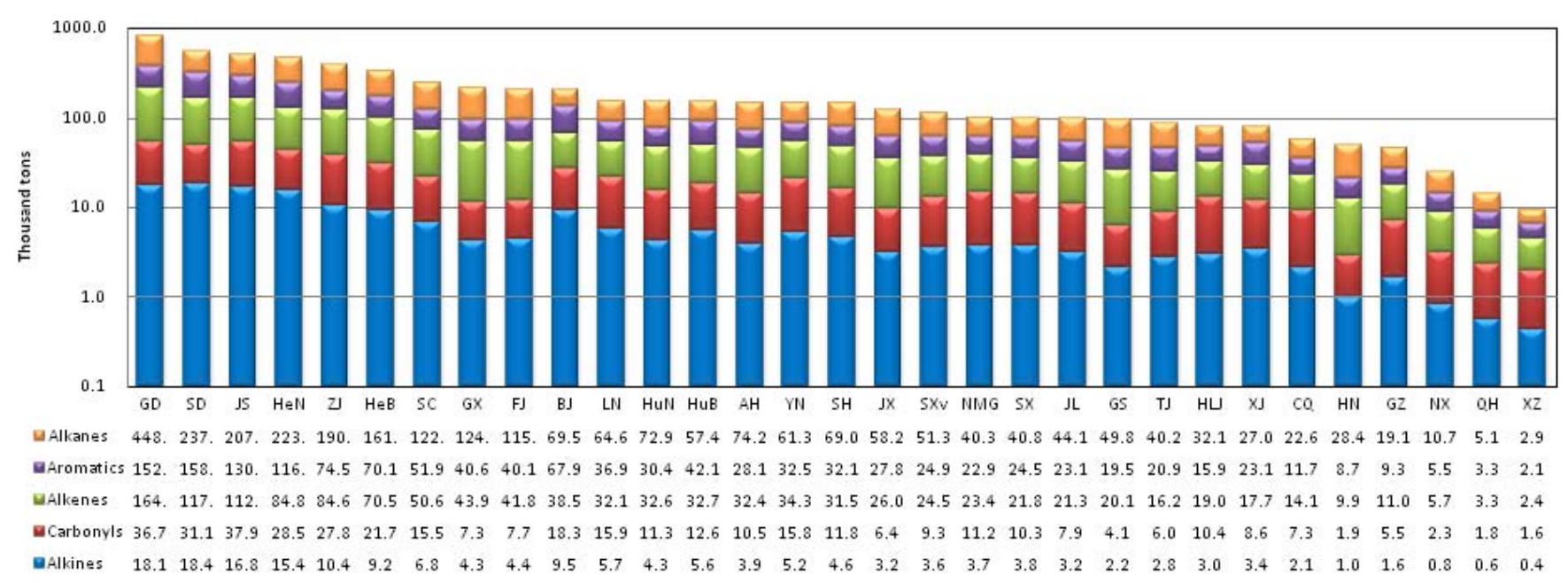

Fig. 3. Provincial emissions (figures in the data table are in thousand tons) and relative proportions of alkanes, alkenes, alkines, aromatics and carbonyls in 2005. The acronyms for the province names are: GD (Guangdong), SD (Shandong), HeN (Henan), JS (Jiangsu), ZJ (Zhejiang), HeB (Hebei), GX (Guangxi), SC (Sichuan), FJ (Fujian), AH (Anhui), HuN (Hunan), BJ (Beijing), SH (Shanghai), LN (Liaoning), YN (Yunnan), JX (Jiangxi), HuB (Hubei), SXv (Shaanxi), GS (Gansu), JL (Jilin), SX (Shanxi), NMG (Neimenggu), TJ (Tianjin), HLJ (Heilongjiang), HN (Hainan), XJ (Xinjiang), CQ (Chongqing), GZ (Guizhou), NX (Ningxia), QH (Qinghai), XZ (Tibet).

cost-effective NMVOC control measures focusing on the control of compounds with high ozone-forming potentials, rather than merely on the reduction of the mass of NMVOC emitted, to reduce the contributions of NMVOC to troposphere ozone formation.

Aromatic hydrocarbons and their degradation products play an important role in urban air pollution (Jeffries et al., 1995) and they are important precursors for tropospheric ozone formation due to their high reactivities (Hoekman, 1992). Emission fractions of twelve aromatics were estimated. Figure $4 \mathrm{c}$ shows that toluene, m,p-xylene, benzene, 1,2,4-trimethylbenzene, o-xylene, m,p-ethyltoluene and ethylbenzene were the dominant constituents, accounting for $91.2 \%$ of the total aromatic emissions. The remaining $8.8 \%$ of aromatic emissions were ascribed to propylbenzene, 1,3,5-trimethylbenzene, 1,2,3-trimethylbenzene, styrene and o-ethyltoluene. Particularly, benzene, toluene, ethylbenzene, $\mathrm{o}-\mathrm{xylene}$, and m,p-xylene (collectively, BTEX), known as hazardous air pollutants, contributed as high as $76.8 \%$ to the total emission, which revealed that vehicular aromatic emissions in China were both highly reactive and highly toxic.

Carbonyls, which include aldehydes and ketones, are oxygenated hydrocarbons with high reactivities, and many aldehydes and ketones are themselves toxic and are known human carcinogens. Emission fractions of nine carbonyls were estimated. Figure $4 \mathrm{~d}$ showed that the most abundant constituents were formaldehyde, acetaldehyde, benzaldehyde, acetone, propionaldehyde and acrolein, responsible for $95.4 \%$ of the total carbonyl emission in 2005 , while the remaining $4.6 \%$ of emissions were ascribed to valeraldehyde, butyraldehyde and methylethylketone. High level of highly reactive compounds was a notable characteristic of China's carbonyl emissions, since the low molecular weight con- stituents of formaldehyde, acetaldehyde and acetone, which have been identified as key photochemical species readily to form photochemical oxidants particularly in rural and remote environments (Martin et al., 1999), contributed as high as $79.3 \%$ to the total carbonyl emission.

In sum, high proportion of light molecular weight compounds with high reactivities and toxicity is a remarkable characteristic of China's speciated NMVOC emissions, mainly due to the high emission fractions of the highly reactive ethene, propene and 2-methyl-2-butene from alkenes, toxic formaldehyde, acetaldehyde, benzaldehyde and acrolein from carbonyls, and toxic and highly reactive BTEX, 1,2,4-trimethylbenzene and m,p-ethyltoluene from aromatics.

Emission compositions of speciated NMVOC groups at the provincial level varied to some extent, due to different provincial vehicle compositions. Detailed compositions and the dominant constituents of the provincial emissions of alkanes, alkenes and alkines, aromatics and carbonyls in 2005 were discussed, as illustrated by Fig. 5, to provide evidences for the effective control of local emissions and the reduction of the most abundant and hazardous constituents.

The composition of provincial alkane emissions shown by Fig. 5a revealed that i-pentane, pentane, butane, isopentane and 2-methylpentane were the dominant constituents in each province. Particularly, i-pentane was the most abundant species in almost all provinces except in Beijing, Hubei, Jiangsu Shandong and Xinjiang, where provincial proportions of i-pentane were only $1.2-5.9 \%$, much less than the 9.9-18.7\% in other provinces.

Ethene, 2-methyl-2-butene, propene, ethyne, trans-2butene and trans-2-pentene were the dominant constituents of provincial emissions of alkenes and alkines, as shown by 


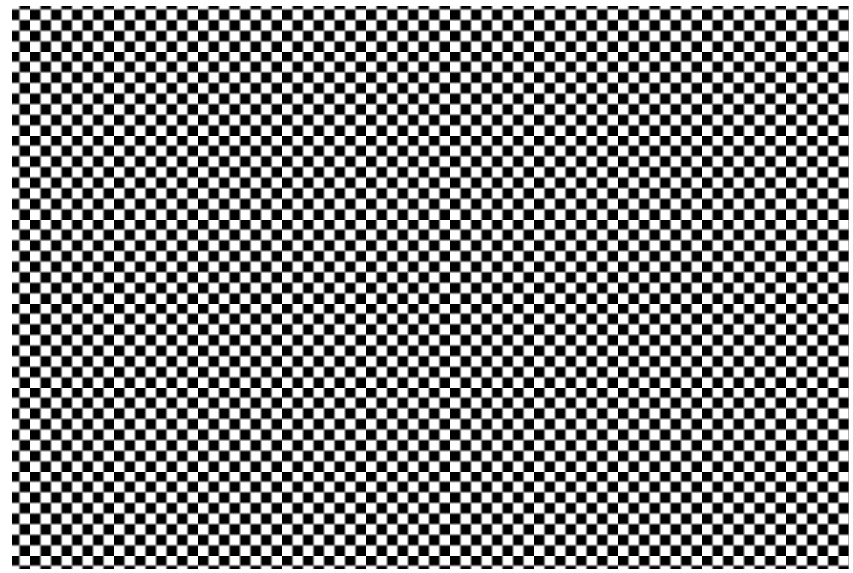

(c)

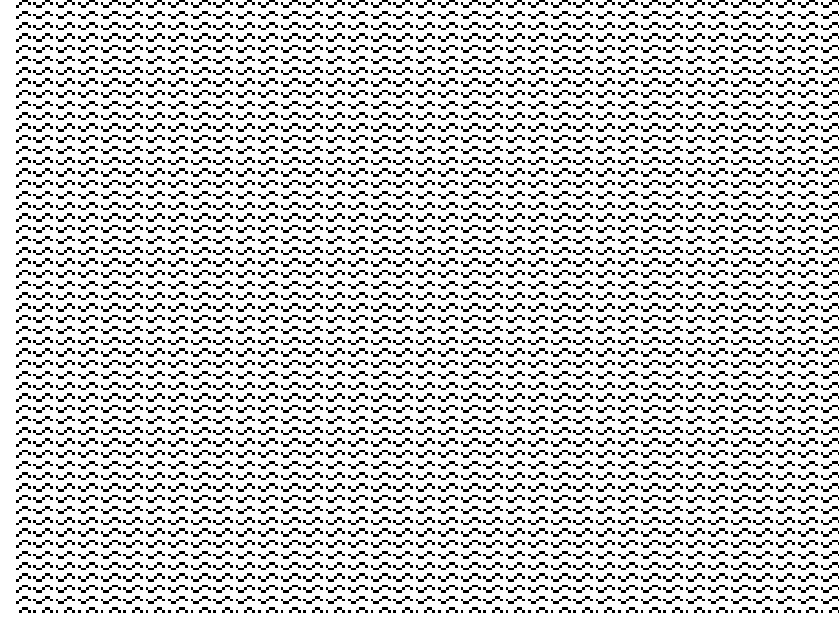

(b)

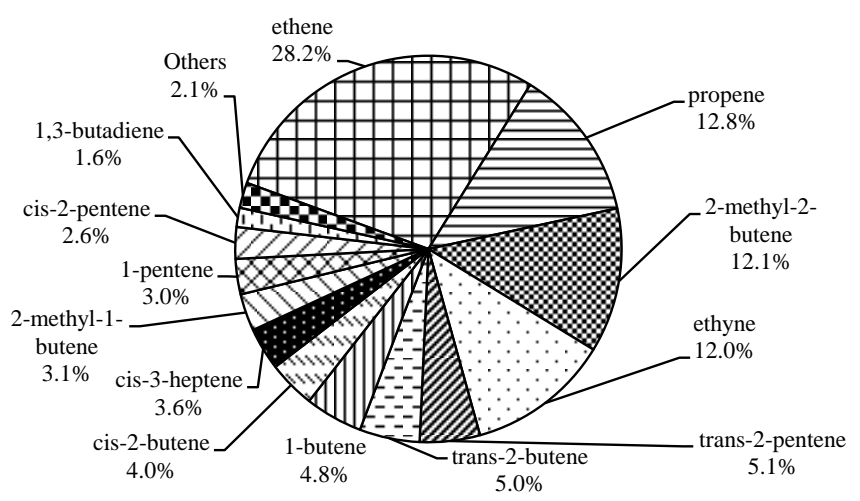

(d)

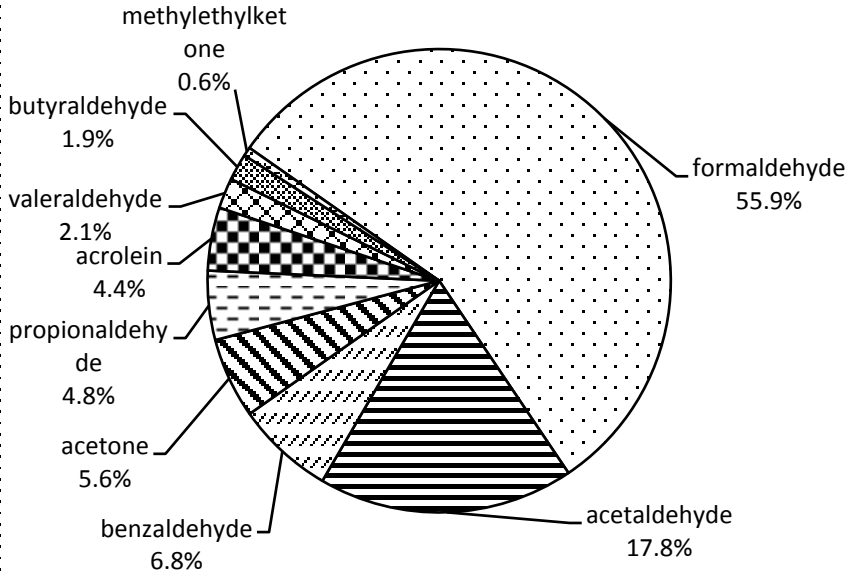

Fig. 4. Emission fractions of specific species within speciated NMVOC groups: (a) alkanes; (b) alkenes and alkines; (c) aromatics; and (d) carbonyls for the year 2005, based on the national emissions.

Fig. 5b. However, the proportions of specific species varied: provincial proportions of ethene increased from $20.5 \%$ in Guangxi to $49.6 \%$ in Tibet, while fractions of 2-methyl2-butene in Beijing and Tibet were both only $2.6 \%$, much less than the average $7.2 \%$ in other provinces. The major cause for this discrepancy of emission compositions among provinces was the diverse compositions of provincial vehicle categories that had distinct NMVOC emission profiles.

Toluene, m,p-xylene, benzene, m,p-ethyltoluene and 1,2,4-trimethylbenzene were the dominant species of aromatics in all provinces, as shown by Fig. 5c. Relative proportions of specific aromatic species among provinces showed little variance, and the provincial fractions of BTEX had a minor difference ranging from $72.7 \%$ in Chongqing to $82.6 \%$ in Henan.

Figure 5d shows that formaldehyde was the most abundant species of carbonyls, and accounted for about 54.5-60.7\% in all provinces, followed by acetaldehyde, the provincial fractions of which ranged from $14.2 \%$ in Henan to $19.9 \%$ in Chongqing.

\subsection{Spatial distribution of reactive and toxic species}

Emissions of aromatics, alkenes and carbonyls that have an important impact on air quality and human health due to their high atmospheric reactivities and high toxicity, were gridded at a resolution of $40 \mathrm{~km} \times 40 \mathrm{~km}$ by means of the GIS methodology for the years 1985, 1995 and 2005, as illustrated by Fig. 6, to provide necessary data for air quality simulation and human health risk assessment by atmospheric chemistry and transportation models and exposure models. A significant contrast between the high-emission eastern areas and the low-emission western regions is revealed by Fig. 6, which was one notable characteristic of the spatial distribution of China's speciated NMVOC emissions of alkenes, aromatics and carbonyls. Besides, regions with high emissions mainly concentrated in cities, which was in agreement with the fact that vehicles in China concentrated in urban areas. Particularly, the Beijing-Tianjin-Hebei region, the Yangtze River Delta and the Pearl River Delta were the most polluted areas located in the prosperous eastern and southern coastal 


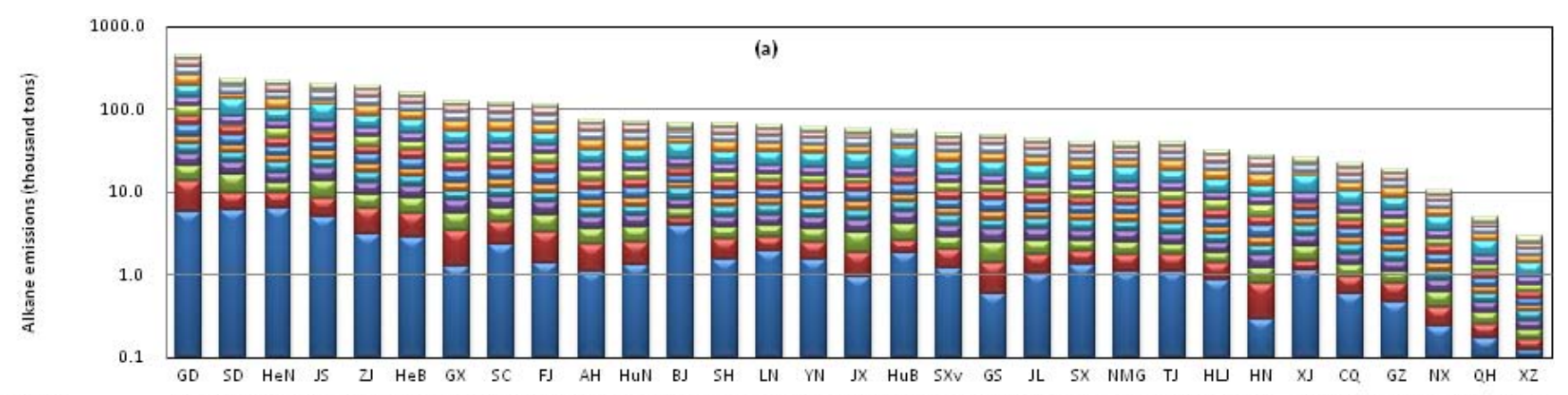

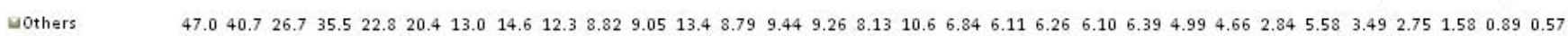
Mi-pentane upentane mbutane Misopentane $\begin{array}{llllllllllllllllllllllllllllllllllll}81.3 & 7.54 & 38.9 & 9.84 & 31.3 & 23.1 & 21.1 & 19.8 & 19.4 & 12.1 & 11.4 & 3.92 & 11.1 & 8.70 & 7.61 & 5.71 & 1.39 & 7.54 & 6.53 & 5.44 & 5.55 & 4.50 & 6.70 & 5.17 & 5.26 & 0.31 & 3.12 & 2.90 & 1.24 & 0.51 & 0.31\end{array}$ w3-methylpentane whexane

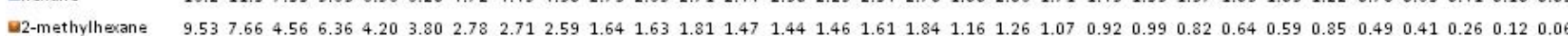

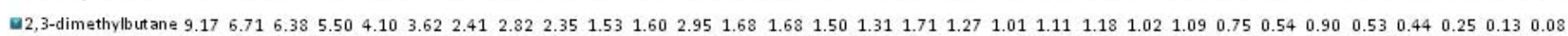

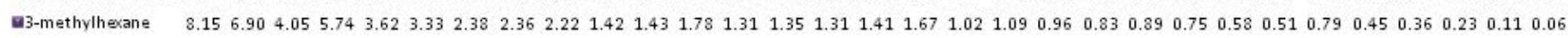

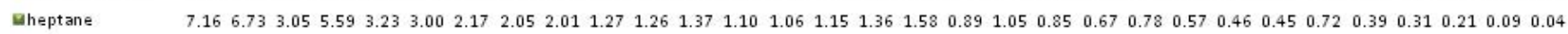

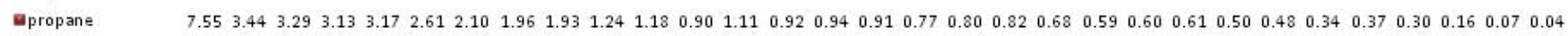

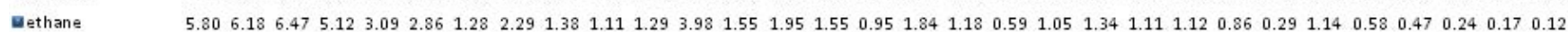

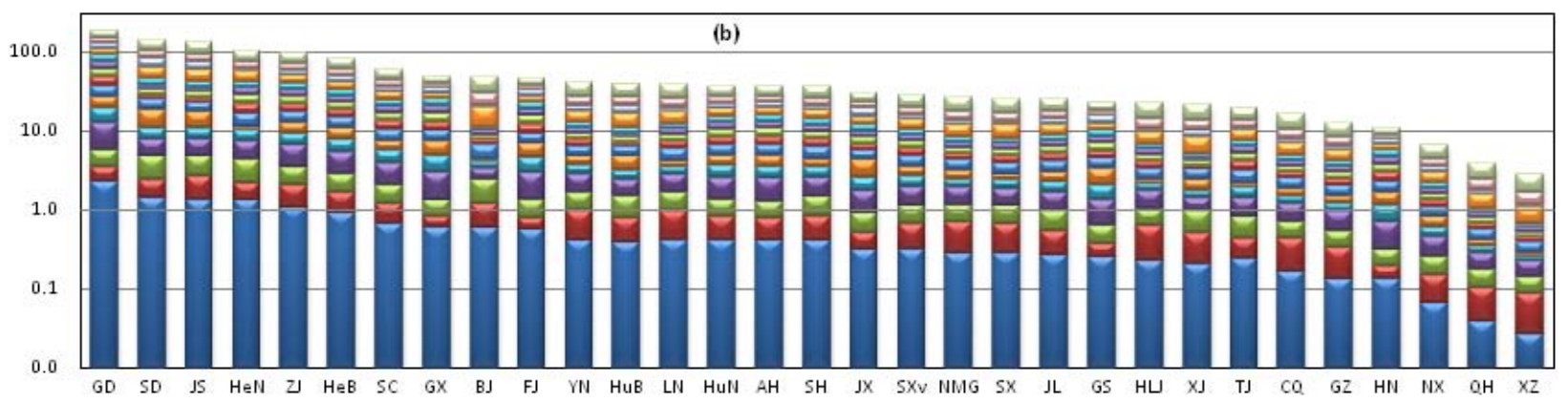

Wethene

Upropene

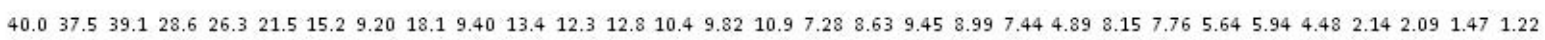

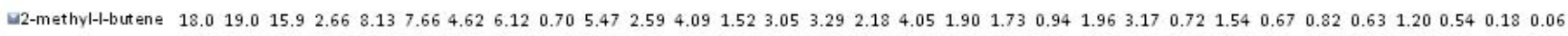
Wethyne $\quad 17.217 .4 \quad 15.914 .8 \quad 9.97 \quad 8.78 \quad 6.53 \quad 4.06 \quad 9.14 \quad 4.17 \quad 5.015 .36 \quad 5.53 \quad 4.09 \quad 3.724 .45 \quad 3.07 \quad 3.46 \quad 3.55 \quad 3.69 \quad 3.08 \quad 2.03 \quad 2.88 \quad 3.27 \quad 2.74 \quad 2.03 \quad 1.58 \quad 0.93 \quad 0.79 \quad 0.55 \quad 0.42$

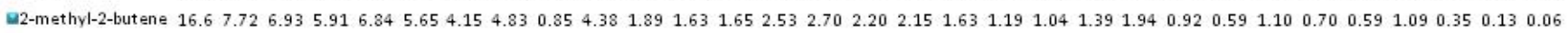

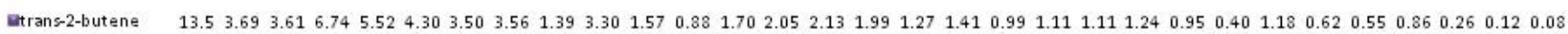

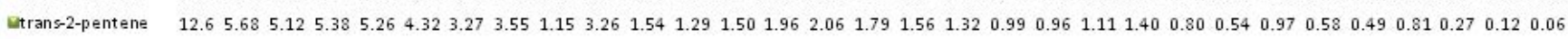

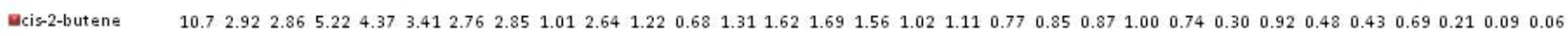
a1-butene ucis-3-heptene acis-2-pentene a1-pentene w1,3-butadiene w1-hexene wothers

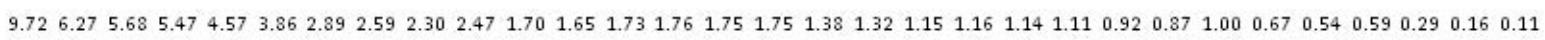

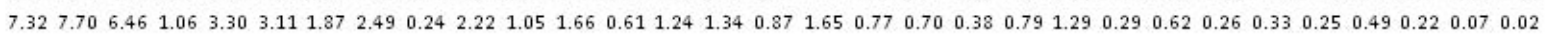
$\begin{array}{llllllllllllllllllllllllllllllllllllllllll}6.52 & 3.09 & 2.77 & 2.78 & 2.73 & 2.26 & 1.70 & 1.84 & 0.63 & 1.69 & 0.81 & 0.70 & 0.78 & 1.02 & 1.07 & 0.93 & 0.82 & 0.69 & 0.52 & 0.50 & 0.58 & 0.73 & 0.42 & 0.30 & 0.50 & 0.30 & 0.26 & 0.42 & 0.14 & 0.06 & 0.03\end{array}$ $\begin{array}{lllllllllllllllllllllllllllllllllllllllll}6.47 & 3.05 & 3.20 & 3.02 & 3.14 & 2.49 & 1.85 & 1.70 & 0.93 & 1.59 & 1.17 & 0.88 & 1.11 & 1.19 & 1.22 & 1.13 & 0.83 & 0.85 & 0.78 & 0.73 & 0.71 & 0.70 & 0.70 & 0.47 & 0.58 & 0.50 & 0.40 & 0.40 & 0.19 & 0.11 & 0.08\end{array}$

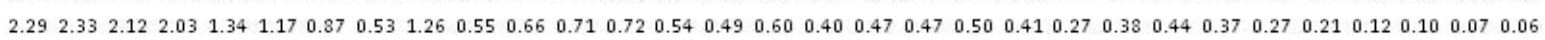

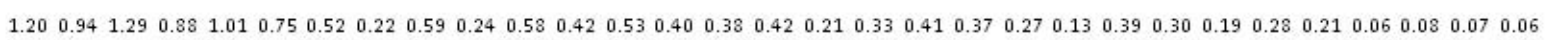
$\begin{array}{lllllllllllllllllllllllllllllllllllllllll}2.23 & 1.43 & 1.31 & 1.31 & 1.07 & 0.90 & 0.67 & 0.58 & 0.59 & 0.56 & 0.41 & 0.38 & 0.42 & 0.41 & 0.41 & 0.42 & 0.31 & 0.31 & 0.28 & 0.28 & 0.27 & 0.25 & 0.23 & 0.21 & 0.24 & 0.16 & 0.13 & 0.13 & 0.07 & 0.04 & 0.03\end{array}$

Fig. 5. Provincial emissions (figures in the data tables are in thousand tons) and the compositions of (a) alkanes, (b) alkenes and alkines, (c) aromatics and (d) carbonyls in 2005. 


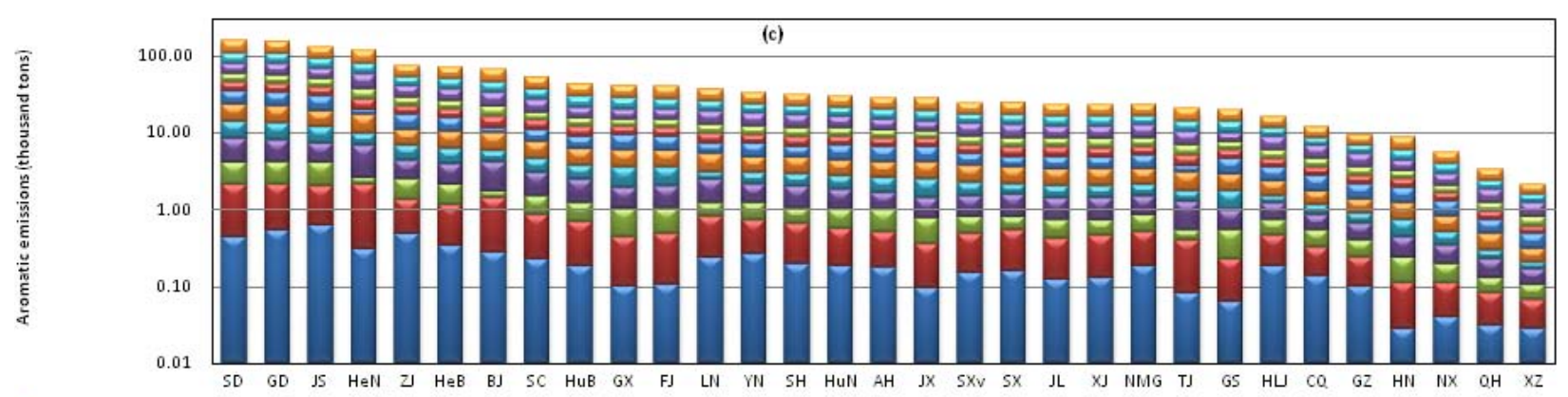

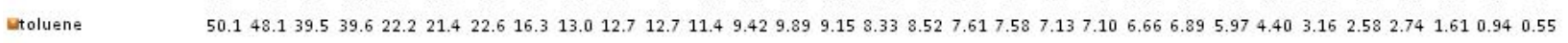

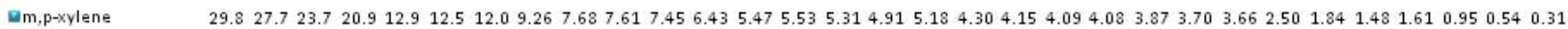
Ebenzene $\quad 21.3 \quad 22.218 .419 .411 .710 .511 .58 .046 .195 .37 \quad 5.486 .385 .505 .334 .794 .35 \quad 3.684 .064 .27 \quad 3.65 \quad 3.70 \quad 3.893 .50 \quad 2.513 .06 \quad 2.14 \quad 1.691 .22 \quad 0.88 \quad 0.590 .42$

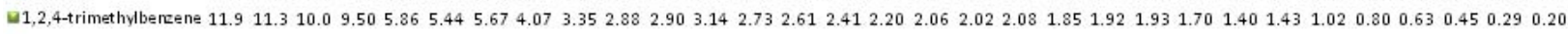

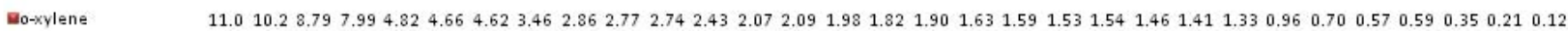

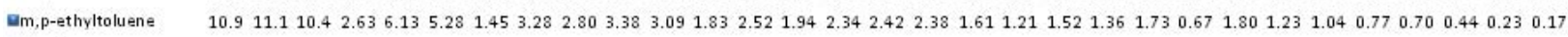

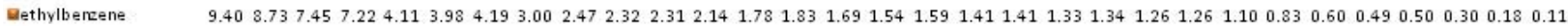

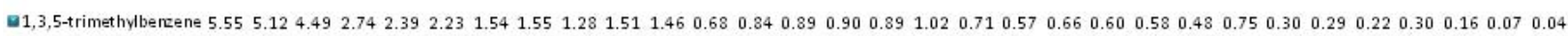

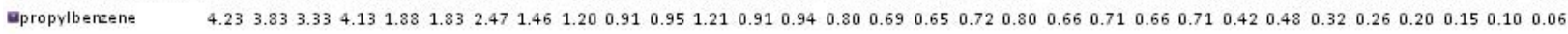

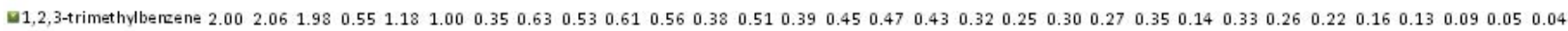

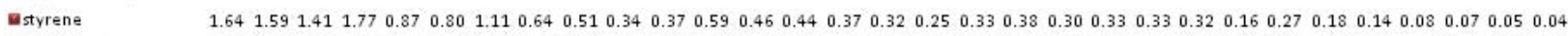

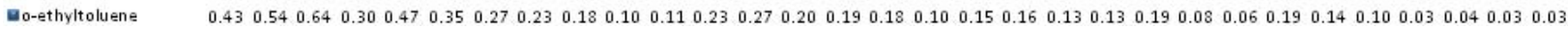

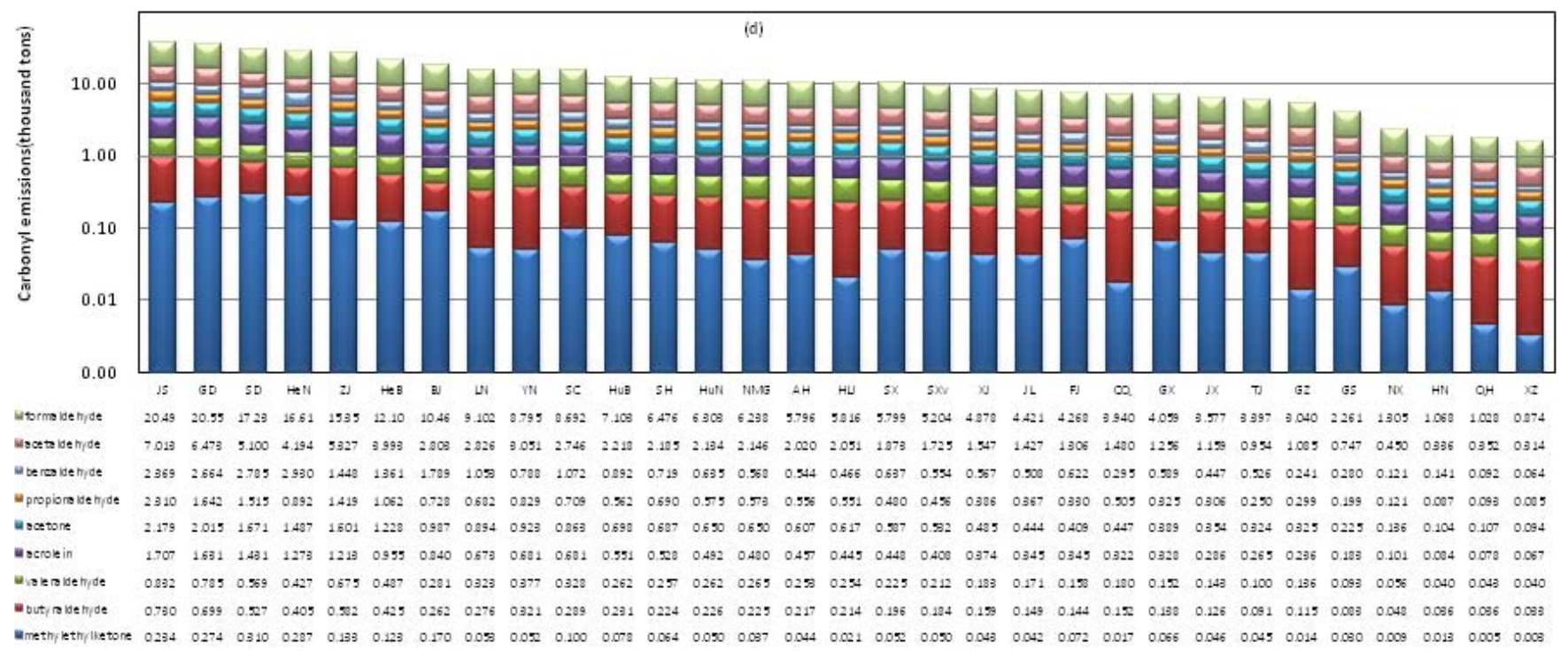

Fig. 5. Continued.

China with most of China's mega cities, which coincided well with the finding that China has faced tremendous increase in air pollutant emissions in mega cities and their immediate vicinities, due to rapidly expanding economic development (Chan and Yao, 2008). In contrast, the northwestern region, which covers $31.8 \%$ of China's territory, generated only about $5-7 \%$ of the total emissions during the period of 1980-2005. This characteristic of spatial distribution was fundamentally caused by the unbalanced economic development across China.
Figure 6 illustrates that the emissions of alkenes, aromatics and carbonyls mainly peaked over the large urban areas, and annual variation of the spatial distribution of emissions revealed that the regions of high emission density had been expanding during the period of 1985-2005, resulting in more areas with especially high emission densities, as shown by Fig. 6, which was another typical and important characteristic of spatial distribution of speciated NMVOC emissions in China. From 1985 to 2005, the proportion of gridded areas with alkene emission density higher than $2000 \mathrm{~kg} / \mathrm{km}^{2}$ (kilograms per square kilometer) increased from $0.21 \%$ to $6.4 \%$, and the proportions of gridded areas with emission densities 
(a) Alkenes

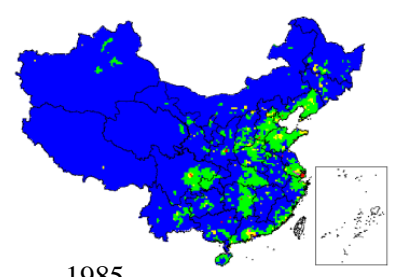

1985

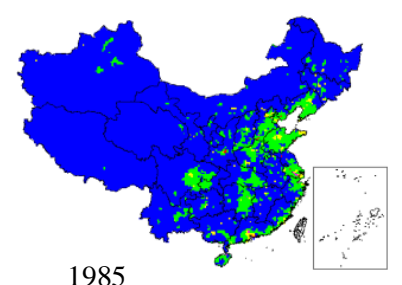

1985

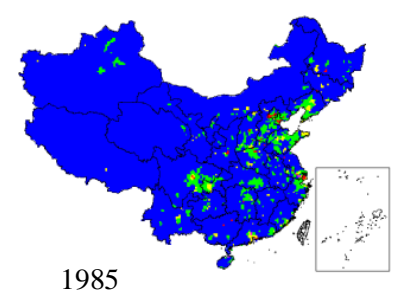

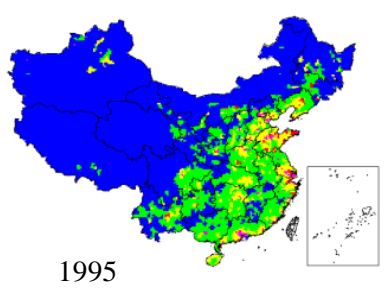

(b) Aromatics

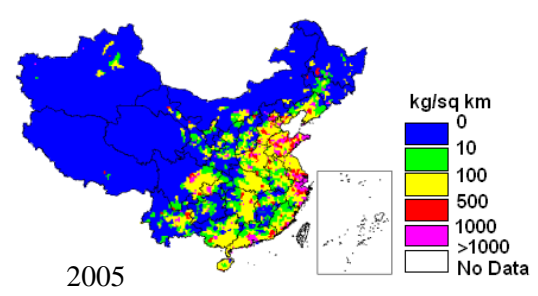

2005

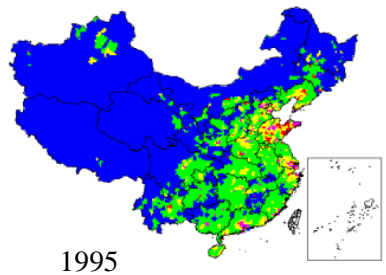

(c) Carbonyls

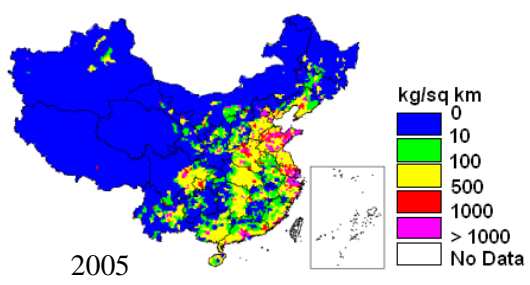

2005
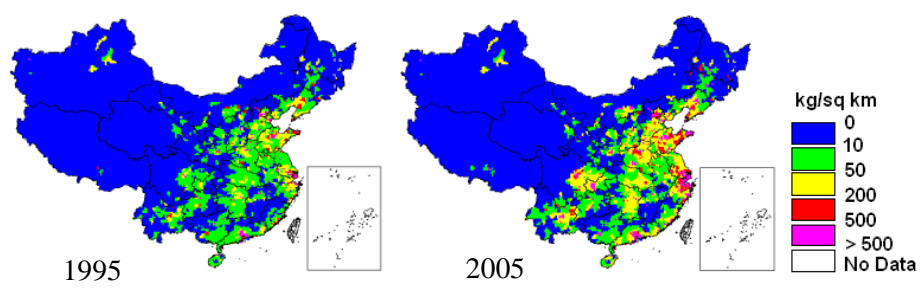

Fig. 6. Spatial distribution of emissions of (a) alkenes, (b) aromatics and (c) carbonyls at a resolution of $40 \mathrm{~km} \times 40 \mathrm{~km}$ for the years 1985 , 1995 and 2005, based on GIS methodology.

of aromatics and carbonyls higher than $1000 \mathrm{~kg} / \mathrm{km}^{2}$ and $500 \mathrm{~kg} / \mathrm{km}^{2}$, respectively, increased from $0.85 \%$ and $0.77 \%$, respectively, to $10.1 \%$ and $7.6 \%$, respectively. Therefore, emission control and reduction in the developed regions of China must be emphasized while marvelous economic prosperity was achieved there.

Different parts of China are significantly unbalanced in economic development levels and area coverage, based on which China's thirty-one provinces can be grouped into six distinct regions: the Southeastern Region, including the provinces of Guangdong, Guangxi, Hainan, Fujian, Zhejiang, Jiangsu, and Shanghai; the Northeastern Region including the provinces of Heilongjiang, Jilin, and Liaoning; the Northwestern Region including the provinces of Xinjiang, Shaanxi, Gansu, Qinghai, and Ningxia; the Southwestern Region including the provinces of Sichuan, Yunnan, Guizhou, Chongqing and Tibet; the Northern Region including the provinces of Beijing, Tianjin, Hebei, Shanxi, Neimenggu, Anhui, and Shandong; and the Central Region including the provinces of Henan, Hubei, Hunan, and Jiangxi. Table 4, which summarizes the emission percentages of alkenes, aromatics and carbonyls, as well as the area and GDP percentages of the six regions in 1985, 1995 and
2005 , revealed that the emission proportion of each region dovetailed well with the corresponding GDP proportion: emission proportion in the southeastern region increased significantly with the rapid economic growth during the period of 1985-2005, when emission proportions in the northeastern and northwestern regions decreased with their relatively slow economic growth.

Figure 6 also depicts that the speciated NMVOC emissions in six regions were notably different: the southeastern, northern, and central regions, which altogether cover $35.2 \%$ of China's territory, generated $71.3 \%, 71.5 \%$ and $66.5 \%$ of the emissions of alkenes, aromatics and carbonyls, respectively, in 1985. Twenty years later, contributions of these regions to the emissions of alkenes, aromatics and carbonyls increased to $79.4 \%, 80.7 \%$ and $73.7 \%$, respectively. On the contrary, the western provinces of Tibet, Shaanxi, Gansu, Qinghai, Ningxia, and Xinjiang, which altogether cover $44.6 \%$ of the territory, contributed only $7.7 \%, 8.7 \%$ and $9.5 \%$ to the emissions of the three speciated NMVOC groups, respectively, in 1985, and their contributions decreased to $5.9 \%, 5.8 \%$ and $6.9 \%$, respectively, in 2005. Consequently, high-emission regions became more seriously polluted, with their emission densities and relative emission proportions increasing over the period. 
Table 4. Summary of area coverage percentage (\%), GDP percentages (\%), emission percentages (\%) of alkenes, aromatics and carbonyls of the six regions for years 1985,1995 and 2005.

\begin{tabular}{|c|c|c|c|c|c|c|c|c|c|c|c|c|c|}
\hline \multirow{2}{*}{ Region } & \multirow{2}{*}{ Area } & \multicolumn{4}{|c|}{1985} & \multicolumn{4}{|c|}{1995} & \multicolumn{4}{|c|}{2005} \\
\hline & & GDP & SG1 & SG2 & SG3 & GDP & SG1 & SG2 & SG3 & GDP & SG1 & SG2 & SG3 \\
\hline Southeastern & 8.2 & 30.1 & 28.4 & 28 & 22.9 & 36.7 & 35.3 & 31.6 & 27.4 & 36.9 & 39.4 & 35.5 & 32.3 \\
\hline Northeastern & 8.4 & 12.7 & 12.1 & 11.7 & 14.3 & 10.3 & 8.7 & 8.7 & 10.8 & 9.3 & 5.8 & 5.6 & 8.4 \\
\hline Northwestern & 31.8 & 5.7 & 7.4 & 8.3 & 9.0 & 4.8 & 6.1 & 7.0 & 8.5 & 4.6 & 5.7 & 5.7 & 6.5 \\
\hline Southwestern & 24.6 & 8.6 & 9.3 & 8.5 & 10.2 & 9.3 & 6.2 & 5.7 & 7.9 & 8.6 & 9.1 & 8.0 & 11.3 \\
\hline Northern & 19.3 & 26.3 & 28.7 & 29.6 & 29.5 & 24.3 & 29.9 & 33.4 & 31.5 & 25.8 & 25.8 & 29.1 & 26.9 \\
\hline Central & 7.7 & 16.6 & 14.2 & 13.9 & 14.1 & 14.6 & 13.8 & 13.5 & 14.0 & 14.8 & 14.2 & 16.1 & 14.5 \\
\hline
\end{tabular}

SG1: Alkenes; SG2: Aromatics; SG3: Carbonyls.

\subsection{Comparison of speciated NMVOC emission inventories with previous estimates and uncertainty analysis}

Inventories of NMVOC emissions from major sources including motor vehicles in China were compiled previously (Klimont et al., 2002; Streets et al., 2003; Ohara et al., 2007; Wei et al., 2008; Bo et al., 2008). The differences in the gross NMVOC emissions from transportation and the reasons were summarized by Bo et al. (2008). Thus, we focused on the discrepancy of the determination or selection of vehicular emission profiles, which resulted in some differences in the speciated NMVOC emissions between our estimates and other major work (Klimont et al., 2002; Streets et al., 2003; Wei et al., 2008): the speciation profiles used by Klimont et al. (2002) and Streets et al. (2003) were drawn from the USEPA's SPECIATE database (USEPA, 2000), and we appreciate this method as there were no reliable domestic profiles as alternative options. It is true that the SPECIATE database was information-intensive and widely used in VOC and particulate matter speciation studies. Actually, some profiles (Schauer et al., 2002; Sagebiel et al., 1996) based on which we compiled our emission profiles were included in SPECIATE. However, SPECIATE has not included profiles of motorcycles and on-road gasoline exhaust under different driving cycles. Moreover, SPECIATE profiles were mainly measurements of vehicles filled with American fuel, which has been distinct from domestic fuel in China in terms of the contents of aromatics and alkenes. In contrast, our profiles were compiled based on research conducted in China, Europe and the USA, based on which we believe our results are better representative for Chinese emissions than estimates of specific species selected on the basis of photochemical reactivity and only relying on SPECIATE profiles. As a result, the emissions of ethane, propane, butanes and benzene reported by Klimont et al. (2002) were 85, 263, 543, and 73 thousand tons, respectively, in 2000, compared with our estimates of 31,22, 222 and 111 thousand tons, respectively. This difference that more emissions of alkanes and less emissions of benzene were estimated using the SPECIATE pro- files alone was in accordance with the fuel content difference that gasoline used in China has higher benzene, alkenes and aromatics and lower alkanes than American gasoline. Wei et al. (2008) reported the emissions of 40 species from major sources including transportation for the year 2005, using literature-based emission profiles. The major difference was that we treated the emissions from distinct vehicle categories under different driving modes seperately, and accordingly compiled seven specific emission profiles including more specific species based on a broader literature review. Particularly, Wei et al. (2008) neglected the identification of the emission profile for motorcycles, whose population in China was the largest and contributed tremendous emissions. Therefore, we believe that our compiled emission profiles are better representative of vehicular NMVOC emission characteristics in China and thus assure a better estimation of the real-world emission inventories of speciated NMVOC including as many as 67 species. Besides, the major improvement of these previous studies was that the emissions from major anthropogenic sources were compiled in China, with particular focuses on the atmospheric photochemical reactivity and toxicity of certain specific species. However, for these previous work, they neglected the specific emission factors of various vehicles under different driving cycles as considered in this study, and there was little information on the temporal variation of vehicular speciated NMVOC emissions in China for the past few decades, with the emissions of specific species from different vehicle categories not given in details, leaving the important information of the contributions of various vehicle categories to speciated NMVOC emissions unknown.

Generally, the uncertainty of the estimated emission inventories of speciated NMVOC groups resulted from the uncertainties in the gross NMVOC emissions produced by various vehicle categories and the corresponding emission profiles compiled in this study. Therefore, we calculated the total uncertainties of speciated NMVOC emissions, including the uncertainty in gross NMVOC emissions caused by speed-dependent emission factors and VMT of various vehicle categories, and the uncertainty of NMVOC profiles with 


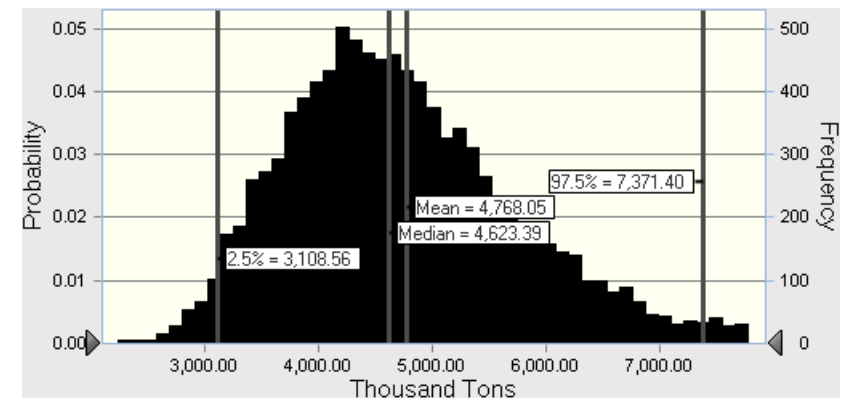

Fig. 7. Probability and frequency distributions of gross emission in 2005, based on a Monte Carlo simulation.

particular consideration of some recent studies which measured the domestic gasoline vapor profiles in China (Lu et al., 2003; Tsai et al., 2006), to better assess the quality of our estimation of speciated NMVOC emissions. The Monte Carlo method, of which the principles and procedures were described elsewhere (Bo et al., 2008), was adopted to conduct the uncertainty analysis. Speed-dependent emission factors and the VMT of various vehicle categories in China from literature reports (He et al., 1998; He, 1999; Hu et al., 2002; Wang et al., 2002; Zhang et al., 2004; He and Wang, 2006; Bo et al., 2008) and our estimates (Cai and Xie, 2007) were used to calculate the uncertainty of the total NMVOC emissions, and the relative weight ratios of specific species from available published literatures were used to calculate the uncertainty caused by the emission profiles. Furthermore, it was assumed that the uncertainties of emission factors, VMT, as well as each specific species contained in the emission profiles had lognormal distributions, and the mean values and the standard deviations for the lognormal distributions of emission factors, VMT and every studied species were calculated. Our main finding was that the $95 \%$ confidence interval for the gross NMVOC emission in 2005 was about $[-48 \%, 24 \%]$, as shown by Fig. 7 . Besides, the uncertainties of alkanes, alkenes, alkines, aromatics and carbonyls caused by emission profiles were found to be $[-29 \%,+8 \%]$, $[-39 \%,+2 \%],[-53 \%,+54 \%],[-34 \%,-3 \%]$, and $[-28 \%$, $+17 \%$ ], respectively, in 2005 at the $95 \%$ confidence level. Thus, the total uncertainties of speciated NMVOC emissions caused by the gross NMVOC emission inventories and the adopted emission profiles were $[-43 \%,+10 \%],[-58 \%$, $+2 \%],[-78 \%,+67 \%],[-50 \%,-4 \%]$, and $[-41 \%,+21 \%]$ for alkanes, alkenes, alkines, aromatics and carbonyls, respectively, in 2005 at the $95 \%$ confidence level, which revealed that the uncertainties of speciated NMVOC emissions were quite acceptable, with an underestimate tendency due to the uncertainties of both gross NMVOC emissions and emission profiles.

\section{Summary and conclusions}

Emission inventories of alkanes, alkenes, alkines, aromatics and carbonyls, five major speciated NMVOC groups, from on-road vehicles were estimated for the period of 19802005, using literature-based NMVOC emission profiles for specific vehicle categories running under particular modes. The emission inventories at the provincial level were further allocated to the county level and gridded at a high resolution of $40 \mathrm{~km} \times 40 \mathrm{~km}$ by means of the GIS methodology, to investigate the characteristics of spatial distribution of emissions, and to provide information for air quality simulation and health risk evaluation by atmospheric chemical and transportation models and exposure models.

Results show that China has experienced an exponential growth of emissions of alkanes, alkenes, alkines, aromatics and carbonyls, which coincided well with China's economic growth. With the persistent and rapid economic growth, the exponentially increasing trend of vehicular emissions continues with the increasing vehicular population stimulated by the expanding demand of owning private cars. Emission contributions of vehicle categories to speciated NMVOC groups showed annual variation, due to the variance in the provincial emissions and in the relative fractions of the seven emission profiles adopted at the provincial level. However, the dominant contributors showed little variance: the primary vehicle categories that contributed most emissions of alkanes, alkenes, alkines and aromatics were motorcycles, due to their huge and ceaselessly growing population and the loose regulations for controlling their evaporation emissions, followed by passenger cars, while the major contributors to carbonyl emissions were heavy duty vehicles mainly burning diesel, followed by motorcycles and passenger cars. Therefore, these primary contributors, especially motorcycles, should be emphasized in priority when designing control and reduction policies for vehicular speciated NMVOC emissions in China.

Compositional characteristics of emissions are essential for understanding the environmental and health impact of pollutants, as well as for formulating effective control measures. Results show that a high emission proportion of light molecular weight compounds with high reactivities and toxicity is a typical characteristic of China's speciated NMVOC emissions, mainly due to the high emission fractions of the highly reactive ethene, propene and 2-methyl-2-butene from alkenes, toxic formaldehyde, acetaldehyde, benzaldehyde and acetone from carbonyls, and toxic and highly reactive BTEX, 1,2,4-trimethylbenzene and m,p-ethyltoluene from aromatics.

Spatial distribution of speciated NMVOC emissions shows a clear difference in emission densities between developed eastern and relatively underdeveloped western and inland China. Remarkably high-emission areas mainly concentrated in the southeastern and northern regions, especially, the Beijing-Tianjin-Hebei region, the Yangtze River Delta and the Pearl River Delta, where most of China's mega cities 
concentrated, were the most polluted areas. Moreover, annual variation of the spatial distribution of emissions revealed that the regions of high emission density had been expanding during the period of 1985-2005, resulting in more areas with especially high emission densities, which was another typical and important characteristic of spatial distribution of speciated NMVOC emissions in China.

Acknowledgements. This work was supported by the financial support from the Research on Optimizing the Stationing of Monitoring Sites for Urban Ambient Air Quality (No. 200709001), from the Research on Key Supporting Technologies of Decision-making of State Environmental Management (No. 2007BAC16B08), from Shanghai Tongji Gao Ting-yao Environmental Science and Technology Development Foundation, and from the Doctoral Thesis Scholarship of China Development Research Foundation funded by General Motors.

Edited by: C. K. Chan

\section{References}

Atkinson, R.: Atmospheric chemistry of VOCs and NOx, Atmos. Environ., 34, 2063-2101, 2000.

Barletta, B., Meinardi, S., Rowland, F. S., Chan, C. Y., Wang, X. M., Zou, S. C., Chan, L. Y., and Blake, D. R.: Volatile organic compounds in 43 Chinese cities, Atmos. Environ., 39, 5979-5990, 2005.

Batterman, S. A., Yu, Y. D., Jia, C. R., and Godwin, C.: Nonmethane hydrocarbon emissions from vehicle fuel caps, Atmos. Environ., 39, 1855-1867, 2005.

Bo, Y., Cai, H., and Xie, S. D.: Spatial and temporal variation of historical anthropogenic NMVOCs emission inventories in China, Atmos. Chem. Phys., 8, 7297-7316, 2008, http://www.atmos-chem-phys.net/8/7297/2008/.

Cai, H. and Xie, S. D.: Estimation of vehicular emission inventories in China from 1980 to 2005, Atmos. Environ., 41, 8963-8979, 2007.

Chan, C. K. and Yao, X. H.: Air pollution in mega cities in China, Atmos. Environ., 42, 1-42, 2008.

Chan, L. Y., Lau, W. L., Zou, S. C., Cao, Z. X., and Lai, S. C.: Exposure level of carbon monoxide and respirable suspended particulate in public transportation modes while commuting in urban area of Guangzhou, China, Atmos. Environ., 36, 5831-5840, 2002.

Conner, T. L., Lonneman, W. A., and Seila, R. L.: Transportationrelated volatile hydrocarbon source profiles measured in Atlanta, JAPCA J. Air Waste Ma., 45, 383-394, 1995.

Duffy, B. L., Nelson, P. F., Ye, Y., and Weeks, I. A.: Speciated hydrocarbon profiles and calculated reactivities of exhaust and evaporative emissions from 82 in-use light-duty Australian vehicles, Atmos. Environ., 33, 291-307, 1999.

European Environment Agency: COPERT III-Computer programme to calculate emissions from road transport, methodology and emission factors (version 2.1), technical report No. 49, 2000.

Fu, X. Q., Weng, Y. B., Qian, F. Z., Ye, W. B., Jin, Y. X., and Chen, Y. Y.: Study of the VOC source profile and benzene compounds emission of various motor vehicles, Acta Scientiae Circumstantiae, 6, 1056-1062, 2008 (in Chinese).

General Administration of Quality Supervision, Inspection and Quarantine of the People's Republic of China: National Standards of Unleaded Gasoline for Motor Vehicles (GB 179301999), 1999.

He, C. Y. and Wang, Q. D.: Vehicle emission factors determination using CMEM in Beijing, Research of Environmental Sciences, 1, 109-112, 2006 (in Chinese).

He, D. Q.: Study on urban vehicular pollution assessment system and emission control target, Ph.D. thesis, Tsinghua University, China, 1999 (in Chinese).

He, D. Q., Hao, J. M., He, K. B., and Fu, L. X.: Vehicle emission factors determination using model calculation, Environmental Science, 3, 9-12, 1998 (in Chinese).

Hoekman, S. K.: Speciated measurements and calculated reactivities of vehicle exhaust emissions from conventional and reformulated gasolines, Environ. Sci. Technol., 26, 1206-1216, 1992.

Hu, B. X., Zhu, H., and Tan, W. X.: A detailed list for exhaust in development models of automobile technology in China, Journal of Wuhan Automotive Polytechnic University, 2, 99-102, 2002 (in Chinese).

Hurley, M. D., Chang, T. Y., Japar, S. M., and Wallington, T. J.: Measurement of VOC reactivities using a photochemical flow reactor, Environ. Sci. Technol., 32, 1913-1919, 1998.

Hwa, M. Y., Hsieh, C. C., Wu, T. C., and Chang, L. F. W.: Realworld vehicle emissions and VOCs profile in the Taipei tunnel located at Taiwan Taipei area, Atmos. Environ., 36, 1993-2002, 2002.

Jeffries, H. E., Yu, J., and Bartolotti, L.: Theoretical and analytical advances in understanding aromatic atmospheric oxidation mechanisms, Abstr. Pap. Am. Chem. S., 210, 15-Phys, 1995.

Klimont, Z., Streets, D. G., Gupta, S., Cofala, J., Fu, L. X., and Ichikawa, Y.: Anthropogenic emissions of non-methane volatile organic compounds in China, Atmos. Environ., 36, 1309-1322, 2002.

Kourtidis, K. A., Ziomas, I. C., Rappenglueck, B., Proyou, A., and Balis, D.: Evaporative traffic hydrocarbon emissions, traffic $\mathrm{CO}$ and speciated HC traffic emissions from the city of Athens, Atmos. Environ., 33, 3831-3842, 1999.

Lei, W.: Study on the driving cycle and emission characteristics of Wuhan light-duty vehicle, MA thesis, Wuhan Polytechnic University, 2007 (in Chinese).

Li, W., Fu, L. X., Hao, J. M., Ma, H., Li, S. Q., and Hu, W.: Emission inventory of 10 kinds of air pollutants for road traffic vehicles in China, Urban Environment and Urban Ecology, 2, 36-38, 2003 (in Chinese).

Liu, X. L. and Ding, Y.: Research of vehicle driving cycle on the road in China's cities, Research of Environmental Sciences, 1, 23-27, 2000 (in Chinese).

Liu, L. H. and Wang, Z.: Characters analysis and planning of small and middle city transport in China, Urban Transport of China, 1, 21-24, 2004 (in Chinese).

Liu, Y., Shao, M., Fu, L. L., Lu, S. H., Zeng, L. M., and Tang, D. G.: Source profiles of volatile organic compounds (VOCs) measured in China: Part i, Atmos. Environ., 42, 6247-6260, 2008.

Lough, G. C., Schauer, J. J., Lonneman, W. A., and Allen, M. K.: Summer and winter nonmethane hydrocarbon emissions from on-road motor vehicles in the midwestern United States, JAPCA 
J. Air Waste Ma., 55, 629-646, 2005.

Lu, S. H., Bai, Y. H., Zhang, G. S., and Ma, J.: Study on the characteristics of VOCs source profiles of vehicle exhaust and gasoline emission, Acta Scientiarum Naturalium, Universitatis Pekinensis, 4, 507-511, 2003 (in Chinese).

Martin, R. S., Villanueva, I., Zhang, J. Y., and Popp, C. J.: Nonmethane hydrocarbon, monocarboxylic acid, and low molecular weight aldehyde and ketone emissions from vegetation in central new Mexico, Environ. Sci. Technol., 33, 2186-2192, 1999.

McLaren, R., Gertler, A. W., Wittorff, D. N., Belzer, W., Dann, T., and Singleton, D. L.: Real-world measurements of exhaust and evaporative emissions in the cassiar tunnel predicted by chemical mass balance modeling, Environ. Sci. Technol., 30, 3001-3009, 1996.

Ministry of Environmental Protection of the People's Republic of China: Technologies and policies on prevention and control of pollution related with vehicular emissions, 1999.

Ministry of Environmental Protection of the People's Republic of China, available at: http://www.mep.gov.cn/tech/hjbz/sywbzgz/ 200703/t20070309_101474.htm, 2007.

Ministry of Environmental Protection of the People's Republic of China, and General Administration of Quality Supervision, Inspection and Quarantine of the People's Republic of China: Limits and Measurement methods for evaporative pollutants from motorcycles and mopeds (GB 20998-2007), 2007.

Ministry of Environmental Protection of the People's Republic of China, and General Administration of Quality Supervision, Inspection and Quarantine of the People's Republic of China: Limits and Measurement methods for the emissions of pollutants from motorcycles on the running mode (GB 14622-2007), 2007.

Ministry of Environmental Protection of the People's Republic of China, and General Administration of Quality Supervision, Inspection and Quarantine of the People's Republic of China: Limits and Measurement methods for the emissions of pollutants from motorcycles on the running mode (GB 14622-2000), 2000.

Mugica, V., Ruiz, M. E., Watson, J., and Chow, J.: Volatile aromatic compounds in Mexico city atmosphere: Levels and source apportionment, Atmosfera, 16, 15-27, 2003.

Na, K., Kim, Y. P., Moon, I., and Moon, K. C.: Chemical composition of major VOC emission sources in the Seoul atmosphere, Chemosphere, 55, 585-594, Chemosphere, 2004.

National Bureau of Statistics: China Statistical Yearbook [M], China Statistical Publishing House, Beijing, 2006.

Nelson, P. F., Quigley, S. M., and Smith, M. Y.: Sources of atmospheric hydrocarbons in Sydney - a quantitative-determination using a source reconciliation technique, Atmos. Environ., 17, 439-449, 1983.

Niedojadlo, A., Becker, K. H., Kurtenbach, R., and Wiesen, P.: The contribution of traffic and solvent use to the total NMVOC emission in a German city derived from measurements and CMB modelling, Atmos. Environ., 41, 7108-7126, 2007.

Ntzaichristos, L. and Samaras, Z.: COPERT3 - computer programme to calculate emissions from road transport, methodology and emission factor (version 2.1), European Environment Agency, Copenhagen, 2000.

Odum, J. R., Jungkamp, T. P. W., Griffin, R. J., Flagan, R. C., and Seinfeld, J. H.: The atmospheric aerosol-forming potential of whole gasoline vapor, Science, 276, 96-99, 1997.
Ohara, T., Akimoto, H., Kurokawa, J., Horii, N., Yamaji, K., Yan, X., and Hayasaka, T.: An Asian emission inventory of anthropogenic emission sources for the period 1980-2020, Atmos. Chem. Phys., 7, 4419-4444, 2007, http://www.atmos-chem-phys.net/7/4419/2007/.

Ossés, D. E., Zah, R., Trivino, R., and Hurni, H.: Spatial accuracy of a simplified disaggregation method for traffic emissions applied in seven mid-sized Chilean cities, Atmos. Environ., 42, 1491-1502, 2008.

Sagebiel, J. C., Zielinska, B., Pierson, W. R., and Gertler, A. W.: Real-world emissions and calculated reactivities of organic species from motor vehicles, Atmos. Environ., 30, 2287-2296, 1996.

Schauer, J. J., Kleeman, M. J., Cass, G. R., and Simoneit, B. R. T.: Measurement of emissions from air pollution sources. 5. C-1-C32 organic compounds from gasoline-powered motor vehicles, Environ. Sci. Technol., 36, 1169-1180, 2002.

Schmitz, T., Hassel, D., and Weber, F. J.: Determination of VOCcomponents in the exhaust of gasoline and diesel passenger cars, Atmos. Environ., 34, 4639-4647, 2000.

Shi, L., Wang, Q. D., and Fu, M. L.: Application of situation of residents travel to estimate vehicles emissions in Beijing, Natural Science Edition, Journal of Beijing Technology and Business University, 2, 12-15, 2009 (in Chinese).

Song, Y., Shao, M., Liu, Y., Lu, S. H., Kuster, W., Goldan, P., and Xie, S. D.: Source apportionment of ambient volatile organic compounds in Beijing, Environ. Sci. Technol., 41, 4348-4353, 2007.

Staehelin, J., Locher, R., Monkeberg, S., and Stahel, W. A.: Contribution of road traffic emissions to ambient air concentrations of hydrocarbons: The interpretation of monitoring measurements in Switzerland by principal component analysis and road tunnel measurements, International Journal of Vehicle Design, 27, 161172, 2001.

Streets, D. G., Bond, T. C., Carmichael, G. R., Fernandes, S. D., Fu, Q., He, D., Klimont, Z., Nelson, S. M., Tsai, N. Y., Wang, M. Q., Woo, J.-H., and Yarber, K. F.: An inventory of gaseous and primary aerosol emissions in Asia in the year 2000, J. Geophys. Res., 108(D21), 8809, doi:10.1029/2002JD003093, 2003.

Tang, J. H., Chan, L. Y., Chan, C. Y., Li, Y. S., Chang, C. C., Wang, X. M., Zou, S. C., Barletta, B., Blake, D. R., Wu., D.: Implications of changing urban and rural emissions on non-methane hydrocarbons in the Pearl River Delta region of China, Atmos. Environ., 42, 3780-3794, 2008.

Tonooka, Y., Kannari, A., Higashino, H., and Murano, K.: NMVOCs and CO emission inventory in east Asia, Water Air Soil Poll., 130, 199-204, 2001.

Tsai, W. Y., Chan, L. Y., Blake, D. R., and Chu, K. W.: Vehicular fuel composition and atmospheric emissions in South China: Hong Kong, Macau, Guangzhou, and Zhuhai, Atmos. Chem. Phys., 6, 3281-3288, 2006, http://www.atmos-chem-phys.net/6/3281/2006/.

Tuia, D., Ossés, D.E., Zah, R., Osses, M., Zarate, E., and Clappier, A.: Evaluation of a simplified top-down model for the spatial assessment of hot traffic emissions in mid-sized cities, Atmos. Environ., 41, 3658-3671, 2007.

US Environmental Protection Agency: SPECIATE Version 3.2, available at http://www.epa.gov/ttn/chief/software/speciate/ speciate32.html, 2000. 
US Environmental Protection Agency.: 1970-2007 Average annual emissions, all criteria pollutants in MS Excel, available at http: //www.epa.gov/ttnchie1/trends, 2008.

Velasco, E., Lamb, B., Westberg, H., Allwine, E., Sosa, G., ArriagaColina, J. L., Jobson, B. T., Alexander, M. L., Prazeller, P., Knighton, W. B., Rogers, T. M., Grutter, M., Herndon, S. C., Kolb, C. E., Zavala, M., de Foy, B., Volkamer, R., Molina, L. T., and Molina, M. J.: Distribution, magnitudes, reactivities, ratios and diurnal patterns of volatile organic compounds in the Valley of Mexico during the MCMA 2002 \& 2003 field campaigns, Atmos. Chem. Phys., 7, 329-353, 2007, http://www.atmos-chem-phys.net/7/329/2007/.

Wadden, R. A., Uno, I., and Wakamatsu, S.: Source discrimination of short-term hydrocarbon samples measured aloft, Environ. Sci. Technol., 20, 473-483, 1986.

Wang, L. Z., Sui, Q., Xie, Q., and Yu, Y. Q.: Definition of emission factor of vehicle in Jinan, Transportation Environmental Protection, 2, 18-20, 2002 (in Chinese).

Wang, Q. D., He, K. B., Yao, Z. L., and Huo, H.: Research in motor vehicle driving cycle of Chinese cities, Environmental Pollution and Control, 10, 745-748, 2007 (in Chinese).

Wei, W., Wang, S. X., Chatani, S., Klimont, Z., Cofala, J., and Hao, J. M.: Emission and speciation of non-methane volatile organic compounds from anthropogenic sources in China, Atmos. Environ., 42, 4976-4988, 2008.

Xie, S. D., Song, X. Y., and Shen, X. H.: Calculating vehicular emission factors with COPERT III model in China, Environmental Science, 27, 3415-3419, 2006 (in Chinese).
Yao, Z. L., Ma, Y. L., He, K. B., Huo, H., and Guo, T.: A study on the real-world vehicle emission characteristics in Ningbo, Acta Scientiae Circumstantiae, 26, 1229-1234, 2006 (in Chinese).

Yao, Z. L., Wang, Q. D., and Hu, Y. X.: Study of vehicle driving cycle on realistic road in Chengdu city, Natural Science Edition, Journal of Beijing Technology and Business University, 1, 1820, 2004 (in Chinese).

Ye, S. B., Wang, Q. D., and He, X.: Tianjin on-road vehicle activity study, Natural Science Edition, Journal of Beijing Technology and Business University, 2, 28-31, 2007 (in Chinese).

Yu, Y. C. and Yu, M. Y.: Estimation and forecast of for-hire motor vehicle emission volume, Journal of Highway and Transportation Research and Development, 6, 154-158, 2008 (in Chinese).

Zhang, K. B. and Ruan, T. Y.: Statistical analysis of the measurement of vehicle driving cycles in China's six cities, Automobile Research and Development, 12, 33-36, 2005 (in Chinese).

Zhang, T.: Analysis on characteristics of the resident trip and study on policy of the transport development in medium or small urban, Transportation Science \& Technology, 3, 89-92, 2005 (in Chinese).

Zhang, Y. H., Shao, M., and Yu, K. H.: Vehicle emissions, environmental impact and control, Chemical Industry Press, Beijing, 2004 (in Chinese).

Zheng, J. Y., Che, W. W., and Wang, Z. L.: Traffic flow and road network-based spatial allocation of regional mobile source emission inventories, Acta Scientiae Circumstantiae, 29, 815-821, 2009 (in Chinese). 